\title{
Increased levels of p70S6 phosphorylation in the G93A mouse model of Amyotrophic Lateral Sclerosis and in valine-exposed cortical neurons in culture
}

\author{
Irene Carunchio $^{\mathrm{a}, \mathrm{b}, 1}$, Livia Curcio ${ }^{\mathrm{a}, \mathrm{b}, 1}$, Massimo Pieri ${ }^{\mathrm{a}, \mathrm{b}}$, Francesca Pica ${ }^{\mathrm{a}}$, Silvia Caioli ${ }^{\mathrm{a}, \mathrm{b}}$, \\ Maria Teresa Viscomi ${ }^{\mathrm{b}}$, Marco Molinari ${ }^{\mathrm{b}}$, Nadia Canu ${ }^{\mathrm{a}, \mathrm{c}}$, Giorgio Bernardi ${ }^{\mathrm{a}, \mathrm{b}}$, Cristina Zona ${ }^{\mathrm{a}, \mathrm{b}, *}$ \\ a Department of Neuroscience, University of Rome "Tor Vergata", Via Montpellier, 1, 00133, Rome, Italy \\ b I.R.C.C.S. Fondazione Santa Lucia, Via del Fosso di Fiorano, 65, 00143, Rome, Italy \\ ' Institute of Neurobiology and Molecular Medicine, CNR, Via del Fosso di Fiorano, 65, 00143, Rome, Italy
}

\section{A R T I C L E I N F O}

\section{Article history:}

Received 25 March 2010

Revised 30 August 2010

Accepted 30 August 2010

Available online 9 September 2010

\section{Keywords:}

Valine

Action potential

Persistent sodium current

mTOR

Cortex

Electrophysiology

\begin{abstract}
A B S T R A C T
The higher risk factor for Amyotrophic Lateral Sclerosis (ALS) among Italian soccer players is a question that is still debated. One of the hypotheses that have been formulated to explain a possible link between ALS and soccer players is related to the abuse of dietary supplements and drugs for enhancing sporting performance. In particular, it has been reported that branched-chain amino acids (BCAAs) are widely used among athletes as nutritional supplements. To observe the possible effect of BCAAs on neuronal electrical properties, we performed electrophysiological experiments on Control cultured cortical neurons and on neurons after BCAA treatment. BCAA-treated neurons showed hyperexcitability and rapamycin was able to suppress it and significantly reduce the level of mTOR, Akt and p70S6 phosphorylation. Interestingly, the hyperexcitability previously reported in cortical neurons from a genetic mouse model of ALS (G93A) was also reversed by rapamycin treatment. Moreover, both G93A and valine-treated neurons presented significantly higher levels of Pp70S6 when compared to control neurons, strongly indicating the involvement of this substrate in ALS pathology. Finally, we performed electrophysiological experiments on motor cortex slices from Control and G93A mice and those fed with a BCAA-enriched diet. We observed that neuron excitability was comparable between G93A and BCAA-enriched diet mice, but was significantly higher than in Control mice.

These findings, besides strongly indicating that BCAAs specifically induce hyperexcitability, seem to suggest the involvement of p70S6 substrate in ALS pathology.
\end{abstract}

(c) 2010 Elsevier Inc. All rights reserved.

\section{Introduction}

Previous published epidemiological studies have reported an increased occurrence of Amyotrophic Lateral Sclerosis (ALS) among Italian soccer players (Armon, 2007; Belli and Vanacore, 2005; Vanacore et al., 2006), although the question is still debated (Armon, 2007). ALS is one of the most common adult-onset neurodegenerative diseases, characterized by progressive and selective degeneration of the upper and lower motorneurons in the motor cortex, brainstem and spinal cord. The cause of this cell-specific loss is still unknown. Although sport participation has been hypothesized as a risk factor for ALS (Armon, 2007; Belli and Vanacore, 2005; Kurtzke and Beebe, 1980), and previous studies have indicated that one or more factors related to professional football in Italy could have a role in determining an increased risk of ALS (Chio et al., 2005; Vanacore

\footnotetext{
* Corresponding author. Department of Neuroscience, University of Rome "Tor Vergata", Via Montpellier, 1, 00133 Rome, Italy. Fax: + 390672596435.

E-mail address: zona@uniroma2.it (C. Zona).

1 These two authors equally contributed to this work.
}

et al., 2006), the eventual relationship between ALS and Italian soccer players is still to be elucidated.

One of the hypotheses regarding the ALS risk is the use of toxic substances and/or of therapeutic drugs employed in excessive doses (Beretta et al., 2003). In particular, branched-chain amino acids (BCAAs, leucine, isoleucine, valine) supplementation is frequently used by athletes to stimulate muscular protein synthesis, to improve mental and physical performance and to accelerate the body's recovery after particularly intense and prolonged sport activities (Ohtani et al., 2006).

BCAAs are easily taken up by the brain (Oldendorf, 1971). They cross the blood-brain barrier via L-system transporters (Smith, 2000) and are taken up by neurons and glia by several transporter systems (Broer, 2006). BCAAs activate glutamate dehydrogenase (GDH), which has been reported to be defective in ALS (Plaitakis, 1990). For this reason three clinical trials were undertaken to test efficacy and safety of BCAAs in ALS patients. All trials failed to show any therapeutic advantage when BCAAs were administered to ALS patients (Platell et al., 2000; Tandan et al., 1996; Testa et al., 1989) and one of these was stopped in 1991 because of the excessive mortality rate among the patients treated with BCAAs (Italian ALS study group, 1993). 
It is known that nutrients, especially BCAAs, modulate the activity of many proteins involved in the control of mRNA translation (Avruch et al., 2001). Several of them are controlled by phosphorylation through signaling events involving the mammalian target of rapamycin (mTOR) (Gulati and Thomas, 2007; Ishizuka et al., 2008). mTOR is a serine/threonine kinase that controls protein synthesis related to cell growth and proliferation (Sandsmark et al., 2007; Sarbassov et al., 2005) and in the brain it may also regulate neuronal development and synaptic plasticity (Tang et al., 2002). Recently, altered mTOR signaling was observed in many cortical malformations, neurodegenerative diseases and epileptogenesis (Inoki et al., 2005; Tsang et al., 2007; Zeng et al., 2008), strongly indicating a role in neurological pathologies.

The aim of the present study was to investigate a possible role of BCAAs and their pathway in the electrophysiological properties of cortical neurons and also to compare BCAA-treated neurons with those obtained from the G93A transgenic mouse model of ALS (Pieri et al., 2009).

\section{Materials and methods}

\section{Animals and treatments}

In this study, B6SJL mice, hereinafter referred to as Control mice, hemizygous transgenic B6SJL-TgN (SOD1-G93A) 1 Gur mice overexpressing the G93A mutant human SOD1 (G93A), B6SJL-TgN (SOD1) 2 Gur mice over-expressing wild-type human SOD1 (SOD1), both constructed by Gurney (Gurney et al., 1994), and originally obtained from Jackson Laboratories (Bar Harbor, Maine, USA), were housed in our animal facilities. Screening for the presence of the human transgene was performed on tail tips from adult mice for the slice recording experiments, and on the body from each embryo after removal of the brain for primary cortical cultures. Monthly western blotting analysis was performed to verify an equal expression of hSOD1 protein in the two transgenic strains (Guatteo et al., 2007).

For the slice recording experiments on the BCAA-treated mice, female and male Control mice were left to mate, and copulation was verified by the presence of sperm in the vaginal smears (plug). On the first day of gestation, females were isolated in individual cages and randomly divided into two groups, receiving either a standard diet or a diet enriched with BCAAs. Both diets were prepared on the basis of 4RF21, standard food, by Mucedola s.r.l. (Milan, Italy), which was purified, autoclaved and sterilized. BCAA-enriched diet contained $2.5 \%$ valine, leucine and isoleucine (1:1:1). BCAA concentration in the diet was selected on the basis of previous reported indications (Italian ALS study group, 1993; Tsubuku et al., 2004).

Animals were fed ad libitum and had free access to drinking water throughout the experiment. The two diets were maintained throughout gestation and lactation. On the 21st day of life the animals were weaned and were fed with the standard diet or the BCAA-enriched diet. Experiments have been carried out in strict accordance with the European Communities Council Directive of 24 November 1986 (86/ $609 / \mathrm{EEC}$ ) regarding the care and use of animals for experimental procedures.

Every effort was made to minimize the number of animals used and any possible suffering caused to them.

\section{Cortical neuron cultures and treatments}

Cortexes were removed from 15-day-old mouse embryos and grown in dissociated cell culture for 8-12 days as previously described (Pieri et al., 2009). Cells were plated in MEM (Minimum Essential Medium, Gibco, Invitrogen, Milan, Italy) supplemented with $5 \%$ fetal bovine serum (FBS, Gibco), 5\% horse serum (HS, Gibco), $25 \mathrm{mM}$ D-glucose (Sigma-Aldrich, Milan, Italy), $2 \mathrm{mM}$ glutamine (Gibco) and $0.1 \mathrm{mg} / \mathrm{ml}$ gentamicin (Sigma-Aldrich) in a cell incubator at $37{ }^{\circ} \mathrm{C}$ with $5 \% \mathrm{CO}_{2} / 95 \%$ air. After $24 \mathrm{~h}$, the medium was replaced with Neurobasal supplemented with B-27 (2\%, Gibco), $0.5 \mathrm{mM}$ glutamine and $0.1 \mathrm{mg} / \mathrm{ml}$ gentamicin (Sigma-Aldrich). Every 3 days the Neurobasal medium supplemented only with B27 was replaced. Cultured neurons were used for patch clamp experiments at 8-day in vitro (DIV). At every Neurobasal replacement, a group of petri dishes were treated with the indicated concentrations of BCAAs, alanine and phenylalanine (Sigma-Aldrich) and/or rapamycin (Calbiochem, San Diego, CA, USA) which were added to the Neurobasal for 2-7 days, as reported in the Results. Neurons from the same culture but exposed for different days to BCAAs were recorded and compared to untreated neurons. All amino acids were dissolved in water and rapamycin in dimethyl sulfoxide (DMSO). In a separate series of experiments we ensured that DMSO concentrations had no effect on evoked responses.

Cellular viability was assessed by counting the number of intact nuclei according to the method described by Volonte et al. (1994). The culture medium was removed and replaced with $1 \mathrm{ml}$ of a detergent containing lysing solution ( $0.5 \%$ ethylhexadecyldimethylammonium bromide, $0.28 \%$ acetic acid, $0.5 \%$ Triton $\mathrm{X}-100,3 \mathrm{mM} \mathrm{NaCl}, 2 \mathrm{mM}$ $\mathrm{MgCl}_{2}$, in PBS pH 7.4 diluted 1/10). After $2 \mathrm{~min}$, the cells were collected and the solution consisted of a uniform suspension of single, intact, viable nuclei that were then quantified by counting in hemocytometer, 2 fields for each sample. Broken or damaged nuclei were not included in the counts.

At least five cultures were used for the measurements of each parameter given in the Results.

\section{Slice preparations}

B6SJL mice, G93A mice and SOD1 mice, fed with normal food or with food enriched with BCAAs, aged 29 postnatal day (P29) to P31, were anaesthetized with halothane (Sigma-Aldrich) and decapitated. Brains were removed and immersed in cold artificial cerebrospinal fluid solution (ACSF) containing the following (in $\mathrm{mM}$ ): $126 \mathrm{NaCl}, 26$ $\mathrm{NaHCO}_{3}, 2.5 \mathrm{KCl}, 1.25 \mathrm{NaH}_{2} \mathrm{PO}_{4}, 2 \mathrm{MgSO}_{4}, 2 \mathrm{CaCl}_{2}$, and 10 glucose, $\mathrm{pH}$ 7.4 gassed with $95 \% \mathrm{O}_{2}-5 \% \mathrm{CO}_{2}$. Coronal slices $(250 \mu \mathrm{m})$ were cut with a vibratome (Leica VT1000S, Wetzlar, Germany) and then incubated in the oxygenated ACSF, initially at $36^{\circ} \mathrm{C}$ for $1 \mathrm{~h}$, and subsequently at room temperature, before being transferred to the recording chamber.

\section{Slice recordings}

Recordings were obtained at $31{ }^{\circ} \mathrm{C}$ from motor cortex layer $\mathrm{V}$ pyramidal neurons visually identified (Stuart et al., 1993), using an upright infrared microscope (Axioskop 2 FS, Carl Zeiss, Germany) by their typical large soma size and the presence of a thick apical dendrite oriented toward the pial surface. Only cells with a typical pyramidal-shaped soma were selected for recordings (Li and Prince, 2002). In order to morphologically identify the recorded cells, some neurons $(n=6)$ were filled with biocytin $(2 \%)$ through the recording pipette. In all cases, only one neuron was impaled in a slice to avoid an overlap of dendritic or axonal arbors of two or more neurons. Only regular-spiking neurons (Contreras, 2004; Steriade, 2004) and those with a membrane resistance lower than $100 \mathrm{M} \Omega$ (Lu et al., 2007) were considered in this study. The slices were continually perfused with ACSF solution bubbled through with $95 \% \mathrm{O}_{2}-5 \% \mathrm{CO}_{2}$, $\mathrm{pH} 7.4$.

Patch clamp electrodes (tip resistance 3-4 M $\Omega$ ) were filled with an intracellular solution containing the following (in $\mathrm{mM}$ ): $145 \mathrm{~K}-$ gluconate, $0.1 \mathrm{CaCl}_{2}, 2 \mathrm{MgCl}_{2}, 10$ HEPES, 1 EGTA, 2 Mg-ATP, pH 7.3 with $\mathrm{KOH}$. After formation of a high-resistance seal $(>1 \mathrm{G} \Omega$ ), capacitance and resistance of electrodes were compensated electronically.

Signals were amplified using a Multiclamp 700B patch clamp amplifier (Molecular Devices, CA, USA), sampled at $20 \mathrm{KHz}$, filtered at $3 \mathrm{KHz}$, and stored in a computer. Data were analyzed using pClamp 10 (Molecular Devices, CA, USA) and Origin 7.0 (Microcal Software, Northampton, MA) software. 
Resting membrane potential was calculated as the mean of $20 \mathrm{~s}$ of current clamp recording. During the current-clamp experimental acquisition, the neuronal membrane potential was shifted to $-70 \mathrm{mV}$ by continuous injection of current, when required, to compare the excitability of different neurons from an equivalent baseline. Capacitance and resistance membrane values were obtained using the Membrane test function of pClamp 10 software.

\section{Reconstruction and morphological analysis of recorded cells}

Immediately after recording, slices containing biocytin-loaded cells were fixed by immersion in $4 \%$ parafolmaldehyde in $0.1 \mathrm{M} \mathrm{PB}$ overnight at $+4{ }^{\circ} \mathrm{C}$. The sections were collected in $\mathrm{PB}$, rinsed three times in the same buffer and then incubated with Cy2-conjugated Streptavidin (1:200; Jackson Immunoresearch Laboratories, USA) in PB $0.3 \%$ Triton $\mathrm{X}-100$ for $3 \mathrm{~h}$ at RT. Fluorescence material was examined under a confocal scanning laser microscope (LSM700 Zeiss, Germany). Coverslips were removed and the slides were further processed for Nissl staining. Bright field observations were performed using a Zeiss Axioskop 2 light microscope equipped with epiillumination fluorescence. Images in bright field microscopy were taken with a digital camera (Nikon; Coolpix 990). Finally, sections were mounted on slides, air-dried and coverslipped with GEL MOUNT (Biomeda, USA). The cytoarchitectonic areas and layers of the different recorded slices were further determined in Nissl-stained sections according to Franklin and Paxinos' Atlas of Mouse Brain (Franklin and Paxinos, 1997) and to Zilles (Zilles, 1985). Figures were generated by adjusting only brightness and contrast, and composed by using Corel Draw 10 software.

\section{Cultured cortical neuron recordings}

Current clamp cortical neuron recordings were obtained with electrodes filled with the same solution used for slice recordings. The bath solution was (in $\mathrm{mM}$ ): $120 \mathrm{NaCl}, 3 \mathrm{KCl}, 2 \mathrm{CaCl}_{2}, 2 \mathrm{MgCl}_{2}, 20$ Dglucose, 10 HEPES, pH 7.3 with $\mathrm{NaOH}$. To record the persistent sodium current, the internal solution was (in $\mathrm{mM}$ ): $130 \mathrm{CsCl}, 20$ tetraethylammonium (TEA)-Cl, $1 \mathrm{MgCl}_{2}, 0.24 \mathrm{CaCl}_{2}, 10$ D-glucose, 5 EGTA, 2 ATP$\mathrm{Mg}, 10$ HEPES, $\mathrm{pH} 7.3$ with $\mathrm{CsOH}$. The external solution was (in $\mathrm{mM}$ ): $120 \mathrm{NaCl}, 3 \mathrm{KCl}, 2 \mathrm{CaCl}_{2}, 10$ HEPES, 20 D-glucose, $2 \mathrm{MgCl}_{2}$, pH 7.3 with $\mathrm{NaOH}$. 4-aminopyridine (4-AP, $2 \mathrm{mM})$ and $\mathrm{CdCl}_{2}(0.2 \mathrm{mM})$ were also added to extracellular medium to block the potassium and calcium currents, respectively. Tetrodotoxin (TTX, Alomone Labs, Jerusalem, Israel) was applied using a multibarrel pipette gravity perfusion system controlled by electronic valves positioned near the recorded neurons' soma using a fast step perfusion system (SF-77B Warner Instruments, Hamden, CT, USA). Sodium persistent current density was calculated by dividing digitized peak current values by the whole-cell capacitance measurements. All recordings were performed at room temperature $\left(22-24^{\circ} \mathrm{C}\right.$ ) and obtained using an Axopatch 200B amplifier (Molecular Devices). pClamp 9 software was utilized for the data acquisition (Molecular Devices). The signals were filtered at 2-10 KHz and digitized at $20-50 \mathrm{KHz}$. After the establishment of a gigaseal, the pipette resistance and capacitance were compensated electronically and the cells accepted for the study only if the relative parameters remained stable (Pieri et al., 2009). The cells chosen for the electrophysiological recordings looked like pyramidal neurons and accounted for more than $80 \%$ of the neuronal population in the culture. All neurons considered in this work for the current clamp experiments responded to current injection with sustained repetitive firing at a frequency that was comparatively linear as a function of the injected current (Contreras, 2004). During current clamp experimental acquisition, the neuronal membrane potential was shifted to $-60 \mathrm{mV}$ when required to compare the excitability of different neurons.

The neuronal membrane potential variation with $-100 \mathrm{pA}$ stimulation was fitted to the single exponential function: $\mathrm{Vm}=\mathrm{Vr}+(\mathrm{Vf}-\mathrm{Vr})$ $\left(1-\mathrm{e}^{\mathrm{t} / \mathrm{tau}}\right)$ where $\mathrm{Vm}$ is the membrane potential, $\mathrm{Vr}$ the resting potential, Vf the final value of the membrane potential, $t$ the time and tau the time constant.

\section{Western blotting}

Cells growing in $3.5 \mathrm{~cm}$ diameter dishes were rinsed once with cold PBS and lysed on ice for $20 \mathrm{~min}$ in $150 \mathrm{ml}$ of ice-cold RIPA buffer (50 mM Tris-HCl, pH 8; 150 mM NaCl: 1\% Triton; 2 mM EDTA; 0.1\% SDS) plus proteases inhibitor cocktail and phosphatase inhibitor cocktail (Sigma-Aldrich, Oakville, Ontario, Canada P5726/P2850). After clearing the lysates by centrifugation at $13,000 \mathrm{~g}$ for $10 \mathrm{~min}$, protein concentration was determined using the Bio-Rad RC DC protein assay kit. Samples containing 30-50 $\mu$ g of protein were resolved by SDS-PAGE 10\% and protein transferred to a nitrocellulose membrane (Hybond-C Amersham Biosciences, Piscataway, NJ). Membranes were blocked in PBS containing 5\% non-fat dried milk for $1 \mathrm{~h}$ at room temperature or overnight at $4{ }^{\circ} \mathrm{C}$. Proteins were visualized using antibodies to mTOR, PmTOR, Akt, PAkt, p70S6 and Pp70S6 (Cell Signaling Technologies, Boston, MA). All primary antibodies were diluted $1: 1000$ in $0.5 \%(\mathrm{w} / \mathrm{v})$ non-fat dry milk, and incubated with the nitrocellulose blot overnight at $4{ }^{\circ} \mathrm{C}$. Incubation with secondary peroxidase coupled anti-rabbit was performed by using the ECL system (Amersham, Arlington Heights, IL, USA). Quantity One software, associated with the versa Doc imaging system (Bio-Rad), was used to quantify resultant bands of interest.

\section{Data analysis}

Data are presented as mean \pm standard deviation (SD). Statistically significant differences were determined using one or two way ANOVA test followed by Bonferroni corrections and Student's unpaired $t$-test or paired $t$-test, when necessary. For statistical tests, values of $\mathrm{P}<0.05$ were considered statistically significant. Statistical analysis was performed using Origin 7 (Microcal Software, Northampton, MA) and SPSS 11.0 for Windows (SPSS Imc. USA) softwares.

\section{Results}

\section{Effects of BCAAs on cortical neuron excitability}

All neurons were recorded at 8-day-old in vitro (DIV). Cortical neurons, cultured under controlled conditions and in the medium to which BCAAs (L-leucine, L-isoleucine, L-valine: $200 \mu \mathrm{M}$ each) were added for 2, 4 and 6 days before being recorded, were not distinguishable from each other under the phase contrast microscope. Current clamp electrophysiological recordings from neurons that looked like pyramidal neurons and that responded to current injection with sustained repetitive firing, as reported in the Materials and methods, were considered for the final analysis (Pieri et al., 2009). In these neurons the passive membrane properties, the pattern of repetitive firing, the time and the voltage threshold values were analyzed. Since for all the parameters considered in this work no significant differences were observed between Control and SOD1 neurons, the two neuronal groups were unified and denoted as Control neurons.

In all tested Control neurons $(n=54)$, in those exposed for 2 days $(n=22), 4$ days $(n=21)$ and 6 days $(n=26)$ to BCAAs, the resting membrane potential was not significantly different (Table 1). In addition, in each of these neurons, the injection of $-100 \mathrm{pA}$ currents (1 s) from the resting membrane potential evoked a response that reached a steady state of potential which was used to calculate the membrane resistance, the membrane time constant $(\tau)$ and the cell capacitance of the cortical neurons (not shown). All these data were comparable for Control, 2-day, 4-day and 6-day neurons exposed to BCAAs (Table 1), indicating that the passive properties of the membrane's cortical neurons were unaffected by the exposure to BCAAs. 
Table 1

Passive membrane properties of Control neurons, 2, 4 and 6 day BCAA-treated neurons. The cells are 8 days old in culture. The membrane time constant (measured at the voltage trace evoked by $-100 \mathrm{pA}$ current injection), the cell capacitance, the input resistance and the resting membrane potential are not statistically different for all conditions (ANOVA test, $\mathrm{P}>0.05$ ).

\begin{tabular}{lllll}
\hline & $\begin{array}{l}\text { Resting membrane } \\
\text { potential }(\mathrm{mV})\end{array}$ & $\begin{array}{l}\text { Resistance } \\
(\mathrm{M} \Omega)\end{array}$ & $\begin{array}{l}\text { Capacitance } \\
(\mathrm{pF})\end{array}$ & $\tau(\mathrm{ms})$ \\
\hline $\begin{array}{l}\text { Control }(\mathrm{n}=54) \\
\text { BCAAs 2 days } \\
(\mathrm{n}=22)\end{array}$ & $-59.7 \pm 4.7$ & $569.2 \pm 198.7$ & $67.4 \pm 12.9$ & $38.1 \pm 14.8$ \\
$\begin{array}{c}\text { BCAAs 4 days } \\
(\mathrm{n}=21)\end{array}$ & $-58.4 \pm 3$ & $593.8 \pm 258.7$ & $69 \pm 26.3$ & $39.5 \pm 21.3$ \\
$\begin{array}{c}\text { BCAAs 6 days } \\
(\mathrm{n}=26)\end{array}$ & $-59.3 \pm 4.2$ & $592.9 \pm 156.9$ & $61.2 \pm 14.7$ & $37 \pm 10.3$ \\
\hline
\end{tabular}

To study the excitability of the single 8-day-old in vitro cortical neuron in control conditions and following BCAA exposure (2-7 days), a current step of $+60 \mathrm{pA}(1 \mathrm{~s})$ was injected to elicit action potentials (Fig. 1A). In all tested cells, the time and the potential threshold were calculated from the first action potential. In cortical neurons exposed for 6 days to BCAAs, the time ( $26.31 \pm 17.91 \mathrm{~ms})$ and the threshold potential $(-44.6 \pm 13.6 \mathrm{mV} ; \mathrm{n}=26)$ differed significantly compared to Control neurons $(43.67 \pm 22.43 \mathrm{~ms},-32.2 \pm 7.6 \mathrm{mV}$, respectively; $\mathrm{n}=54 ; \mathrm{P}<0.05$ with unpaired $t$-test; data not shown), indicating a higher excitability in BCAA-exposed neurons.

In all tested cells, the inverse of the first interspike interval was taken as an estimate of the cell firing frequency and compared between Control, 2, 4, 6 and 7 days treatment with BCAAs. Neurons exposed to BCAAs for 4 or more days presented a significantly higher frequency compared to Control (Fig. 1B). The excitability of 8 day-old Control cortical neurons was compared to that of neurons exposed to BCAAs for 6 days (Fig. 1C). The injection of $+20 \mathrm{pA}$ current $(1 \mathrm{~s}$ ) elicited 3 or 4 action potentials in all recorded neurons exposed for 6 days to BCAA, whereas action potentials were never observed in Control neurons with this stimulation. In contrast, when the current amplitude was raised to $+40 \mathrm{pA}$ or above, multiple action potentials were recorded in all neurons, both Control and BCAA-exposed (Fig. 1C). In all tested cells, the frequency increased when the amplitude of the train-evoking current increased. For all injected currents equal to or above $+40 \mathrm{pA}$, the firing frequency in BCAA neurons $(n=26)$ was significantly greater than that in the Control

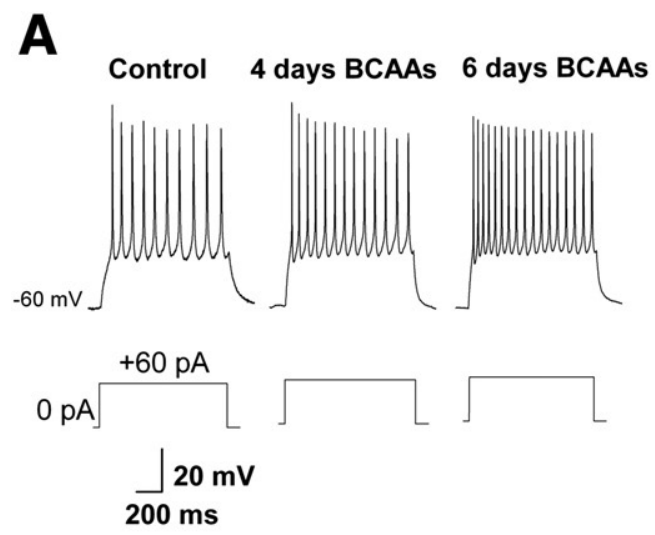

C
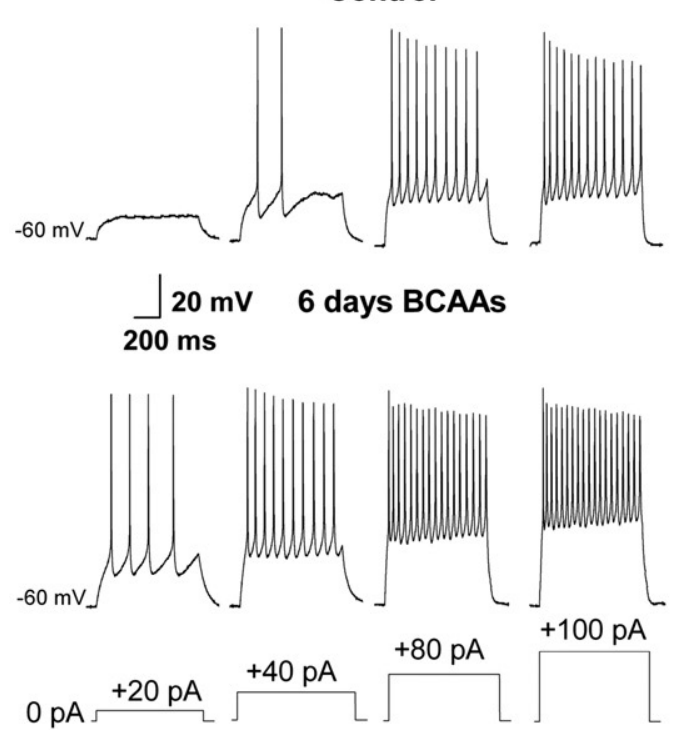

B

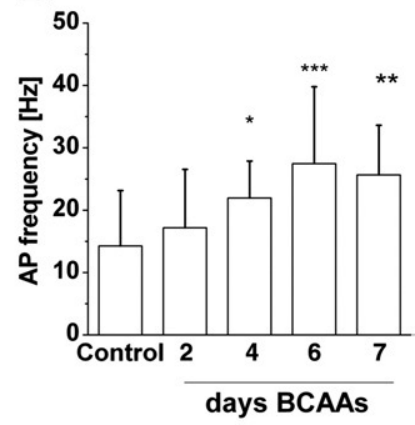

D

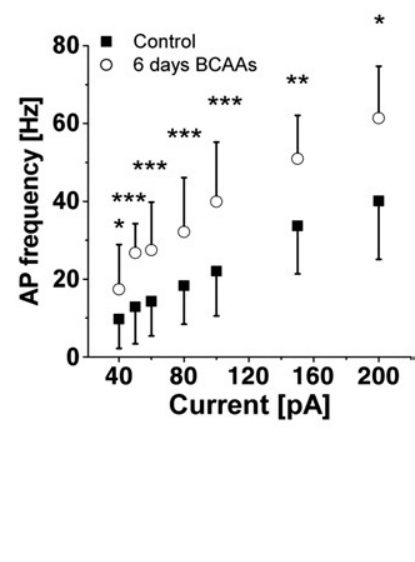

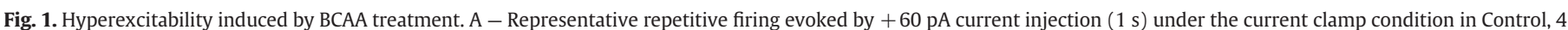

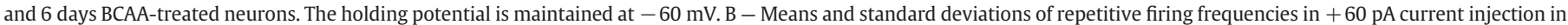

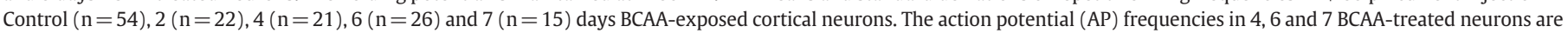

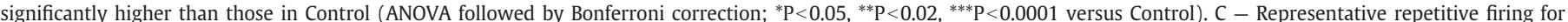

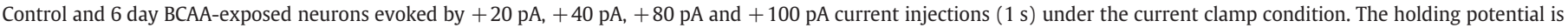

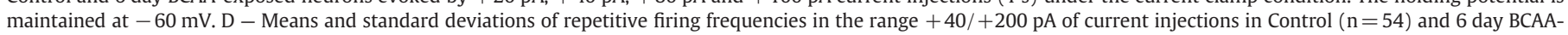
exposed neurons ( $\mathrm{n}=26$; unpaired $t$-Student test, ${ }^{*} \mathrm{P}<0.05$, ${ }^{* *} \mathrm{P}<0.02$, ${ }^{* * *} \mathrm{P}<0.0001$ ). 
condition ( $n=54$; Fig. 1D). Over the range of injected currents tested $(+40 /+200 \mathrm{pA})$, the firing frequency varied from $9.73 \pm 7.53$ to $40.07 \pm 14.99 \mathrm{~Hz}$ in the Control and from $17.37 \pm 11.51$ to $61.36 \pm$ $13.35 \mathrm{~Hz}$ in 6-day BCAA-exposed cortical neurons (Fig. 1D).

Interestingly, the hyperexcitability observed in neurons after 6 days' exposure to BCAAs has also been observed in G93A cortical neurons (Pieri et al., 2009).

\section{Specificity of BCAA effect}

To test whether the observed hyperexcitability was due specifically to the amino acids with the branched-chain or was an effect related also to other amino acids without any lateral chain or with an aromatic chain, for 6 days we exposed cortical neurons to alanine $(200 \mu \mathrm{M})$, phenylalanine $(200 \mu \mathrm{M})$ and to the three branched-chain amino acids valine $(200 \mu \mathrm{M})$, isoleucine $(200 \mu \mathrm{M})$, leucine $(200 \mu \mathrm{M})$, separately. As reported in figure (Figs. 2A, C), the frequencies of Control (14.26 \pm $8.8 \mathrm{~Hz} ; \mathrm{n}=54)$, alanine-added $(13.27 \pm 7.87 \mathrm{~Hz} ; \mathrm{n}=8)$ and phenyl-

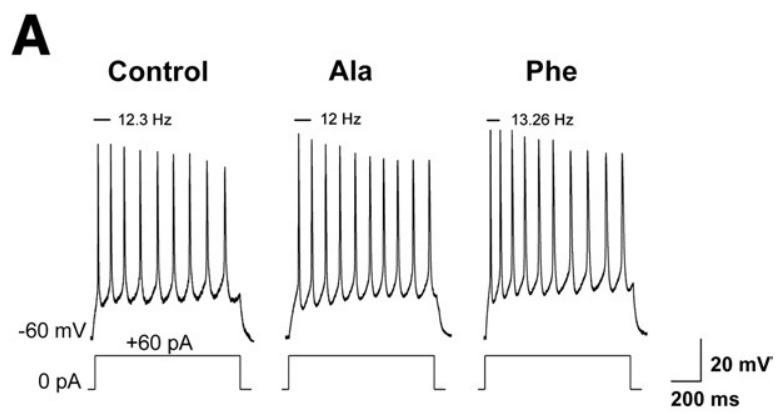

B

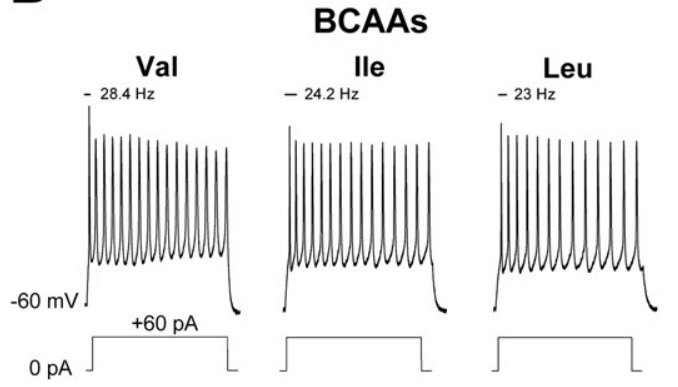

C

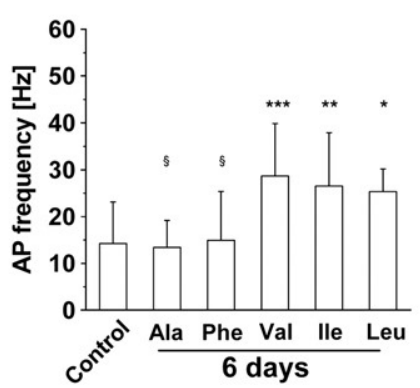

Fig. 2. Specificity of BCAA effect on firing properties A - Representative repetitive firing in Control neuron, 6-day alanine $(200 \mu \mathrm{M})$ and phenylalanine $(200 \mu \mathrm{M})$ exposed neurons and $\mathrm{B}$ - representative repetitive firing in 6-day valine $(200 \mu \mathrm{M})$, isoleucine $(200 \mu \mathrm{M})$ and leucine $(200 \mu \mathrm{M})$ exposed neurons. Responses were evoked by $+60 \mathrm{pA}$ current injections $(1 \mathrm{~s})$ under the current clamp condition from a holding potential of $-60 \mathrm{mV}$. The calculated frequency is reported $(\mathrm{Hz})$ above each trace. $\mathrm{C}-$ Bar histogram showing the means and standard deviations of frequencies in Control neurons, in neurons exposed for 6 days to Ala, Phe, Val, Ile and Leu (200 $\mu \mathrm{M}$, each). The frequencies for Val, Ile and Leu were statistically different compared to Control (ANOVA followed by Bonferroni correction, ${ }^{* *} \mathrm{P}<0.02,{ }^{* * *} \mathrm{P}<0.0001$ versus Control) and the frequency for Val was significantly different compared to Ala and Phe $(\S \mathrm{P}<0.05)$. alanine-added $(14.93 \pm 10.43 \mathrm{~Hz} ; \mathrm{n}=8)$ neurons were not statistically different $(\mathrm{P}>0.05)$ whereas neurons exposed to valine $(28.66 \pm$ $11.19 \mathrm{~Hz} ; \mathrm{n}=20)$, isoleucine $(23.18 \pm 15.92 \mathrm{~Hz} ; \mathrm{n}=9)$ and leucine $(22.47 \pm 11.05 \mathrm{~Hz} ; \mathrm{n}=7)$ presented a significantly higher frequency compared to Control ( $\mathrm{P}<0.02$; Figs. 2B, C). Moreover, we exposed neurons to increasing concentrations $(10 / 300 \mu \mathrm{M})$ of the branchedchain amino acid valine and recorded the neurons at 8 DIV (Fig. 3A). As shown in Fig. 3B, frequency analysis revealed that exposure of cortical neurons to different concentrations of valine for 6 days increased the frequency of action potentials induced by a current step of $+60 \mathrm{pA}$ in a dose-dependent fashion (1 s, Fig. 3B).

All these data indicate that the hyperexcitability observed in cortical neurons exposed to BCAAs is induced specifically by the branched-chain amino acids and that the valine-induced hyperexcitability is dose-dependent.

\section{Rapamycin effect}

Many previous papers indicated that branched-chain amino acids activate mTOR signaling which plays a crucial role in many aspects of cellular functions (Cota et al., 2006; Ishizuka et al., 2008; Proud, 2002; Sarbassov et al., 2006). To verify whether in our experimental conditions mTOR pathway is involved in valine-exposed neuron hyperexcitability, we used rapamycin. Valine treatment $(200 \mu \mathrm{M})$, as shown in Fig. 3, induces a significantly higher frequency compared to Control neurons. This effect in cultured cortical neurons recorded in the same experimental conditions as in Fig. 3, is reduced, but still significantly different by $24 \mathrm{~h}$ of $10 \mathrm{nM}$ rapamycin treatment $(22.5 \pm$ $7.72 \mathrm{~Hz} ; \mathrm{P}<0.02, \mathrm{n}=9$ ), whereas it is completely reversed both with $24 \mathrm{~h}$ treatment at a higher concentration $(50 \mathrm{nM} ; 16.12 \pm 8.93 \mathrm{~Hz}$, $\mathrm{P}>0.05, \mathrm{n}=12$ ) and with 6 days treatment with $2 \mathrm{nM}$ rapamycin $(17.35 \pm 8.87 \mathrm{~Hz} ; \mathrm{P}>0.05, \mathrm{n}=8$; Fig. $4 \mathrm{~A})$. Rapamycin alone ( $10 \mathrm{nM}$ or
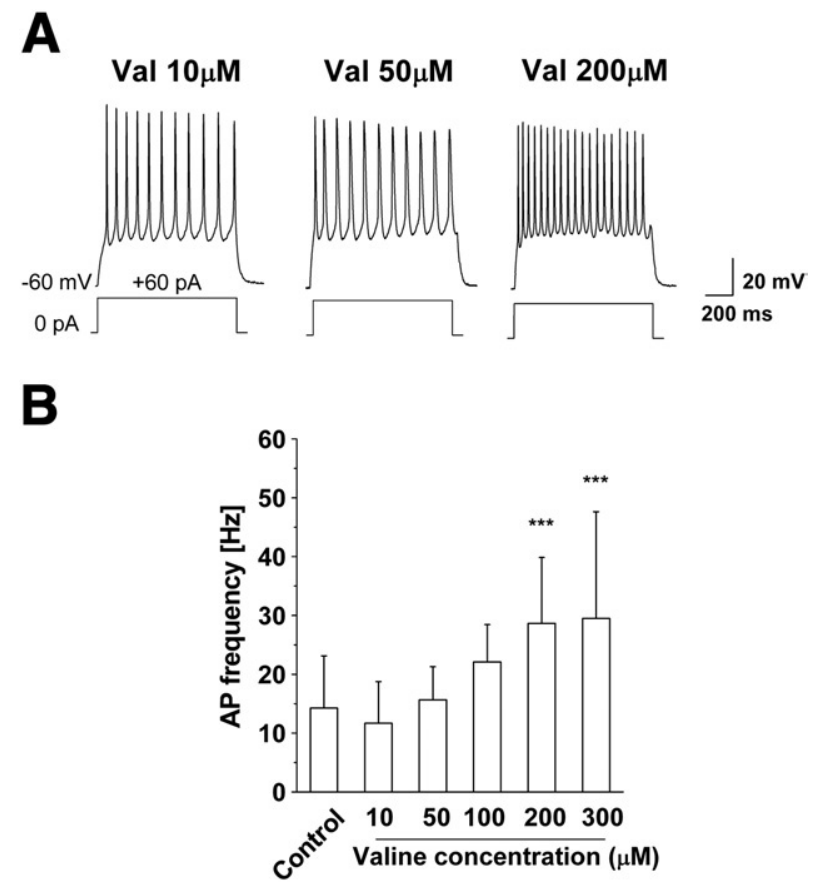

Fig. 3. Dose-response relationship of action potential (AP) frequencies and valine concentrations A - Example traces of 8 DIV cortical neurons exposed for 6 days to 10, 50 and $200 \mu \mathrm{M}$ valine. $\mathrm{B}$ - Bar histogram showing the means and standard deviations of AP frequencies for Control and different concentrations of valine. Values were $14.26 \pm 8.85$ $(\mathrm{n}=54)$ for Control condition; $10.57 \pm 6.39(\mathrm{n}=9)$ for $10 \mu \mathrm{M}$ valine; $15.65 \pm 5.62$ $(\mathrm{n}=13)$ for $50 \mu \mathrm{M}$ valine; $22.09 \pm 6.37(\mathrm{n}=10)$ for $100 \mu \mathrm{M}$ valine; $28.66 \pm 11.20$ $(\mathrm{n}=20)$ for $200 \mu \mathrm{M}$ valine and $28.99 \pm 17.94(\mathrm{n}=12)$ for $300 \mu \mathrm{M}$ valine. The data are statistically different starting from $100 \mu \mathrm{M}$ valine-exposed neurons (ANOVA followed by Bonferroni correction, ${ }^{* * *} \mathrm{P}<0.0001$ versus Control). 
A
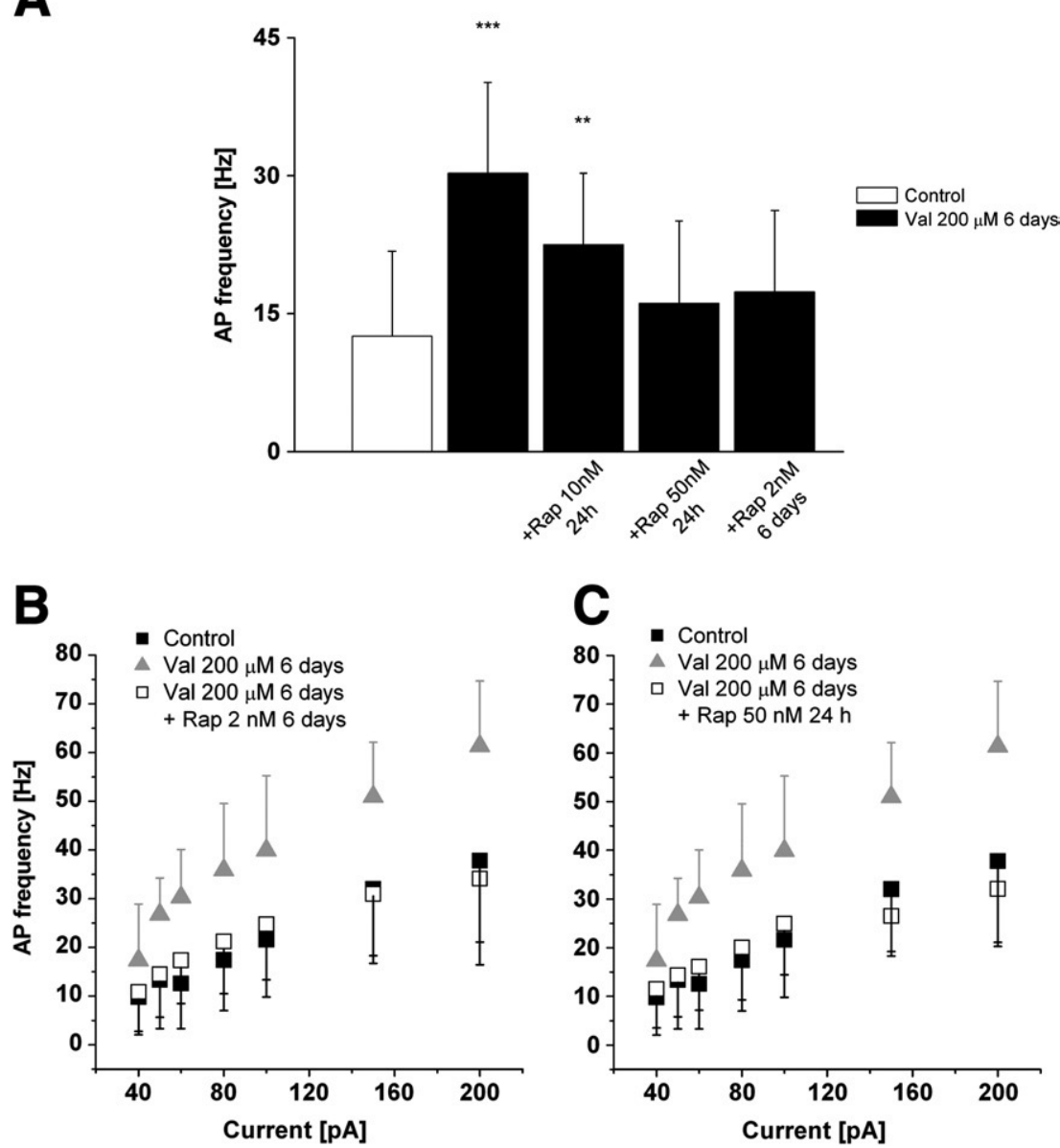

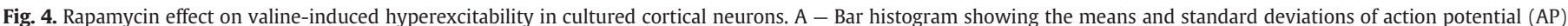

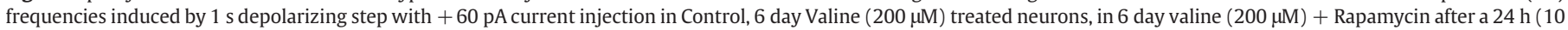

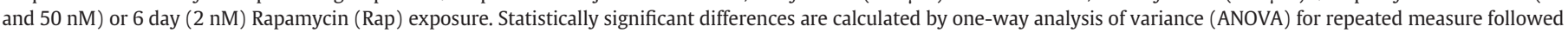

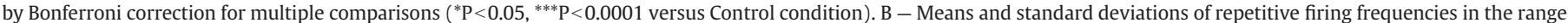

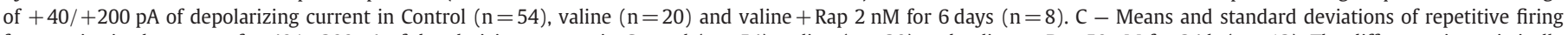

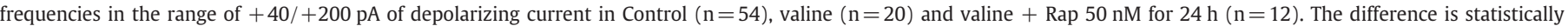
significant (ANOVA test, $\mathrm{P}<0.05$ ) for each current injection.

$50 \mathrm{nM}$ ), added to the control medium for $24 \mathrm{~h}$ or rapamycin alone $(2 \mathrm{nM})$ for 6 days had no effect on neuronal frequency in all tested neurons ( $\mathrm{n}=18$, not shown). To further verify the effect of rapamycin on the action potential frequency, Control neurons $(n=54), 6$ day valine-treated neurons $(200 \mu \mathrm{M} ; \mathrm{n}=20), 6$ day valine- and rapamycin-treated neurons ( $200 \mu \mathrm{M}, 2 \mathrm{nM}$, respectively; $\mathrm{n}=8$ ) were stimulated with increasing current injections. In this condition, rapamycin was able to reverse the cortical valine-induced hyperexcitability (Fig. 4B). The same result was obtained with $24 \mathrm{~h}$ treatment with $50 \mathrm{nM}$ rapamycin (Fig. 4C; $\mathrm{n}=12$ ).

These data show that rapamycin is able to reverse the valineinduced hyperexcitability in a time- and concentration-dependent manner, whereas it has not effect on Control neuron excitability. Consequently, these results seem to indicate an indirect action of rapamycin on the neuronal electrical properties.

\section{G93A cortical neurons rescued from hyperexcitability by rapamycin}

One known feature of ALS patients, also observed in the G93A mouse model of ALS, is cortical hyperexcitability. Indeed, in G93A cortical neurons the action potential frequency, in accordance with our previous results (Pieri et al., 2009), was significantly higher for each current injection compared to Control neurons (Fig. 5). To verify whether rapamycin is also able to reduce G93A cortical excitability, as has been observed in cultured cortical neurons treated with BCAAs, we exposed G93A cortical neurons to $50 \mathrm{nM}$ rapamycin for $24 \mathrm{~h}$. As shown in Figs. 5A and B, rapamycin treatment is able to reduce G93A hyperexcitability to the control values.

Viability of Control and G93A cortical cells following valine- and rapamycin-exposure

To study the cellular viability following the valine- and/or rapamycin-exposure of Control and G93A cultures, 8 day-old cells exposed to valine for 7 days $(200 \mu \mathrm{M})$ and/or rapamycin for $24 \mathrm{~h}$ $(50 \mathrm{nM})$, were treated as reported in the Materials and methods. As shown in Fig. 6, the number of Control and G93A viable cells was not statistically different in normal medium (Control viable cells $=82.3 \pm$ 14.3; G93A viable cells $=73.1 \pm 10.5$ ) and in all considered conditions $(\mathrm{P}>0.05, \mathrm{n}=12$ samples for each condition). These results indicate that, in our experimental condition, valine and rapamycin have no effect on the cellular viability, both in Control and G93A cultures.

Increased levels of Pp70S6 in G93A and valine-treated neurons reversed by rapamycin

To verify a possible modulation of mTOR substrates in G93A and valine-treated neurons compared to Control neurons, we exposed 
A

Control G93A

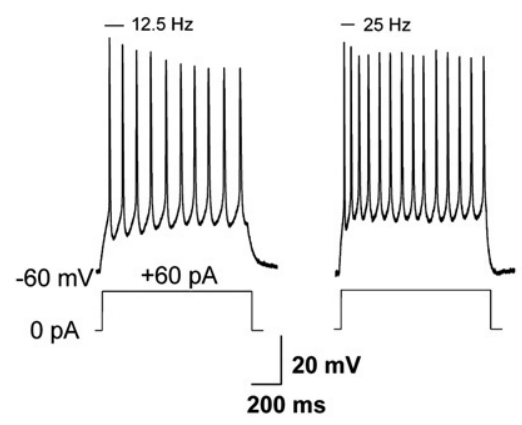

B

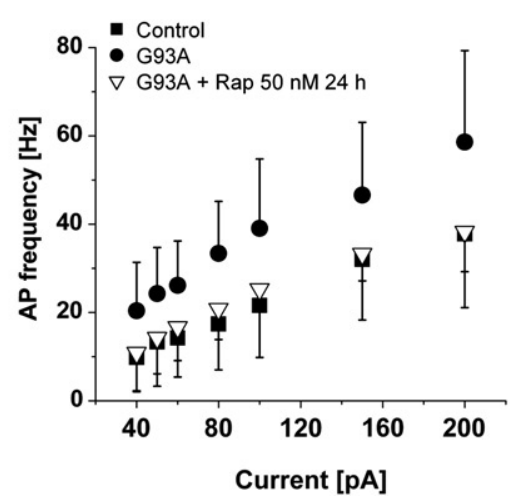

Fig. 5. Rapamycin effect on G93A neurons. In A - are shown representative traces of Control, G93A and G93A treated with $50 \mathrm{nM}$ rapamycin for $24 \mathrm{~h}$, obtained with a $1 \mathrm{~s}$ depolarizing step of $+60 \mathrm{pA}$ current injection. The relative action potential (AP) frequency is reported above each trace. $\mathrm{B}-$ Action potential frequencies plotted against current injections $(+40 /+200 \mathrm{pA})$ for all the conditions shown in A. The treatment of G93A neurons with $50 \mathrm{nM}$ rapamycin for $24 \mathrm{~h}$ significantly decreases the G93A hyperexcitability (ANOVA followed by Bonferroni correction, $\mathrm{P}<0.02$ for each current injection) up to Control values.

G93A and valine-treated neurons to $50 \mathrm{nM}$ rapamycin for $24 \mathrm{~h}$ and performed western blotting analysis.

As reported in Fig. 7, we found that rapamycin successfully suppressed mTOR signaling in all conditions. Indeed, we found that

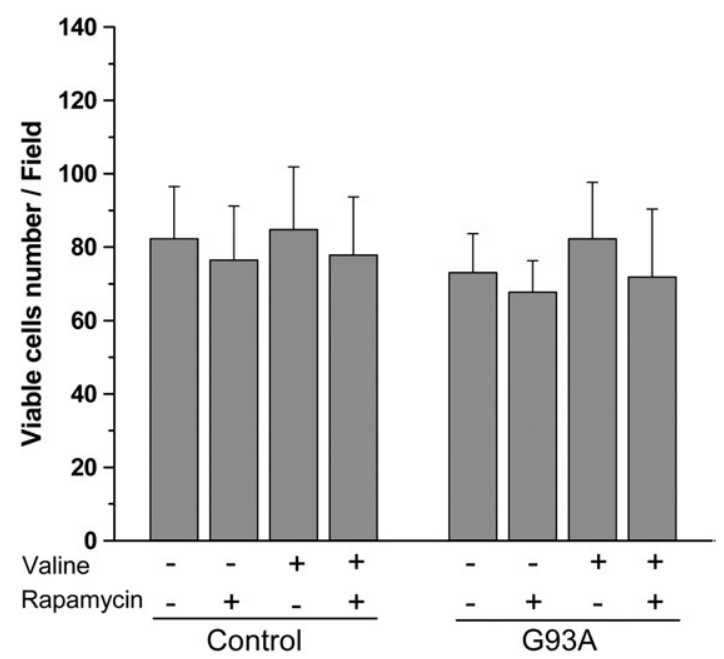

Fig. 6. Cellular viability following valine- and/or rapamycin-exposure. Bar histogram showing the means and SD of the viable cell number/field ( 2 fields from each of the 12 samples obtained from at least 5 different cultures). All the means are not significantly different $(\mathrm{n}=24$ fields for each condition; $\mathrm{P}>0.05$, two way ANOVA). rapamycin was able to significantly reduce the level of mTOR phosphorylation in Control neurons $(0.39 \pm 0.09, n=6)$, in Control neurons treated with valine $(0.4 \pm 0.09, \mathrm{n}=6)$, in G93A neurons $(0.3 \pm$ $0.08, \mathrm{n}=6)$ and in G93A neurons treated with valine $(0.35 \pm 0.08$, $\mathrm{n}=3 ; \mathrm{P}<0.01$; Fig. 7B), compared to untreated Control neurons. We found that rapamycin also strongly reduced the phosphorylation of p70S6, a target of mTORC1 known to regulate cell growth by inducing protein synthesis, in Control, G93A and valine-treated neurons. Phosphorylation of Akt was also slightly reduced. Interestingly, Control neurons treated with valine and G93A neurons both presented significantly higher levels of Pp70S6 compared to untreated neurons. In addition, G93A neurons treated with valine showed an increase of Pp70S6 comparable to that observed in G93A untreated neurons. These data indicate, for the first time, that neurons from the G93A mouse model of ALS and valine-treated neurons both show higher levels of Pp70S6 protein compared to Control and that these levels are reduced by rapamycin.

\section{Persistent voltage-dependent $\mathrm{Na}^{+}$current}

Since persistent voltage-dependent $\mathrm{Na}^{+}$current $\left(\mathrm{I}_{\mathrm{NaP}}\right)$ is known to be involved in neuronal excitability, and previous papers showed that in G93A neurons the hyperexcitability was due to an increase in this current (Kuo et al., 2005; Pieri et al., 2009; van Zundert et al., 2008), we performed experiments aimed at studying whether this current is involved in BCAA-induced hyperexcitability. To isolate the $\mathrm{I}_{\mathrm{NaP}}$ and to analyze its biophysical properties in Control and in cortical neurons exposed for 6 days to BCAAs (Val-Leu-Ile, $200 \mu \mathrm{M}$, each), we performed whole-cell recordings from 8 day-old in vitro neurons. We utilized a slow ramp $(<20 \mathrm{mV} / \mathrm{s})$ protocol to prevent activation of the fastdecaying $\mathrm{Na}^{+}$current component, under experimental conditions in which $\mathrm{Ca}^{2+}$ and $\mathrm{K}^{+}$currents were pharmacologically blocked (see Materials and methods). When the slow voltage ramp from $-100 \mathrm{mV}$ to $+30 \mathrm{mV}(14 \mathrm{mV} / \mathrm{s})$ was applied to cortical neurons, the recorded currents increased relatively linearly in the sub-threshold region near rest because of the passive leak current, but at more depolarized levels, between -65 and $-60 \mathrm{mV}$, the current usually deviated downward from the extrapolated leak current (Fig. 8A). This incoming current was completely and reversibly suppressed by the sodium channel blocker tetrodotoxin (TTX, $1 \mu \mathrm{M}$; Fig. $8 \mathrm{~A}$, inset) and then identified as $\mathrm{I}_{\mathrm{NaP}}$. Current-voltage curves for $\mathrm{I}_{\mathrm{NaP}}$ in Control neurons $(\mathrm{n}=15)$ and in neurons exposed for 6 days to BCAAs $(n=18)$ were obtained from the differences between the slow current amplitudes before and after exposure to TTX (Fig. 8A). The continuous I-V relationship indicated that the voltage-dependent activation threshold of the $\mathrm{I}_{\mathrm{NaP}}$ was similar in both Control and BCAA-treated neurons $(-59.98 \pm 5.82 \mathrm{mV}$; $-61.24 \pm 4.53 \mathrm{mV}$, respectively; $\mathrm{P}>0.05)$ and also the peak potential was similar (Control: $-37.53 \pm 7.65 \mathrm{mV}$; BCAAs: $-39.03 \pm 4.61 \mathrm{mV}$; $\mathrm{P}>0.05$ ). However, $\mathrm{I}_{\mathrm{NaP}}$ amplitude measured at the peak of the $\mathrm{I} / \mathrm{V}$ relationship was significantly higher in BCAA-treated cortical neurons $(39.94 \pm 14.03 \mathrm{pA})$ than in those of Control $(22.32 \pm 12.26 \mathrm{pA}, \mathrm{P}<0.05)$ as was the current density (Control: $0.49 \pm 0.24 \mathrm{pA} / \mathrm{pF}$; BCAAs: $0.78 \pm$ $0.31 \mathrm{pA} / \mathrm{pF} ; \mathrm{P}<0.05$; Fig. $8 \mathrm{~B}$ ). These data indicate that the persistent sodium current increases in BCAA-treated neurons and is involved in the observed hyperexcitability.

Hyperexcitability in G93A cortical slices and in those of BCAA-treated mice

Neuronal hyperexcitability has also recently been reported in slices from the G93A mouse model of ALS. Hyperexcitability has actually been observed in postnatal G93A mouse brainstems (van Zundert et al., 2008). To verify whether the cortical hyperexcitability observed in cultured neurons is also present in postnatal G93A mice, we performed current clamp electrophysiological recordings from P29-31 male mice. 
A

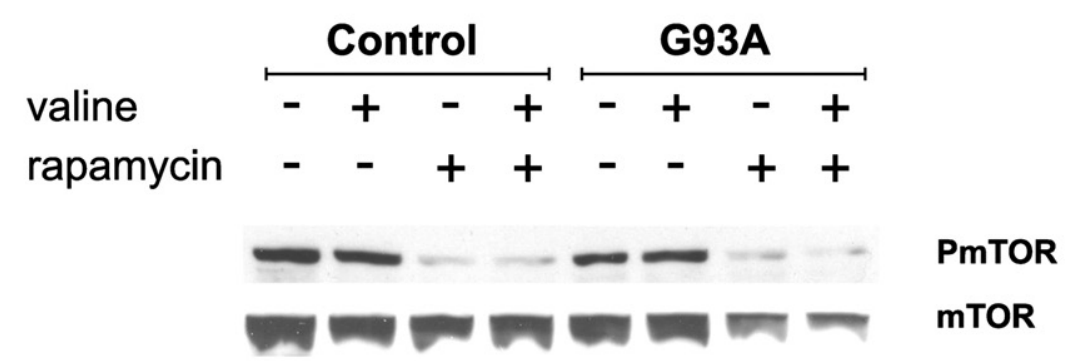

PAkt
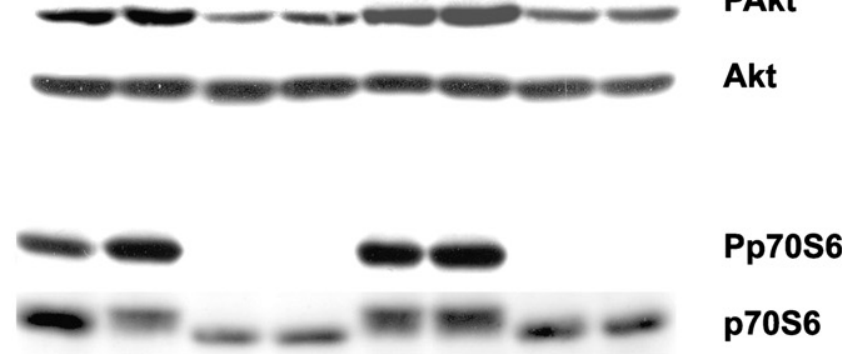

$\beta$-actin

B

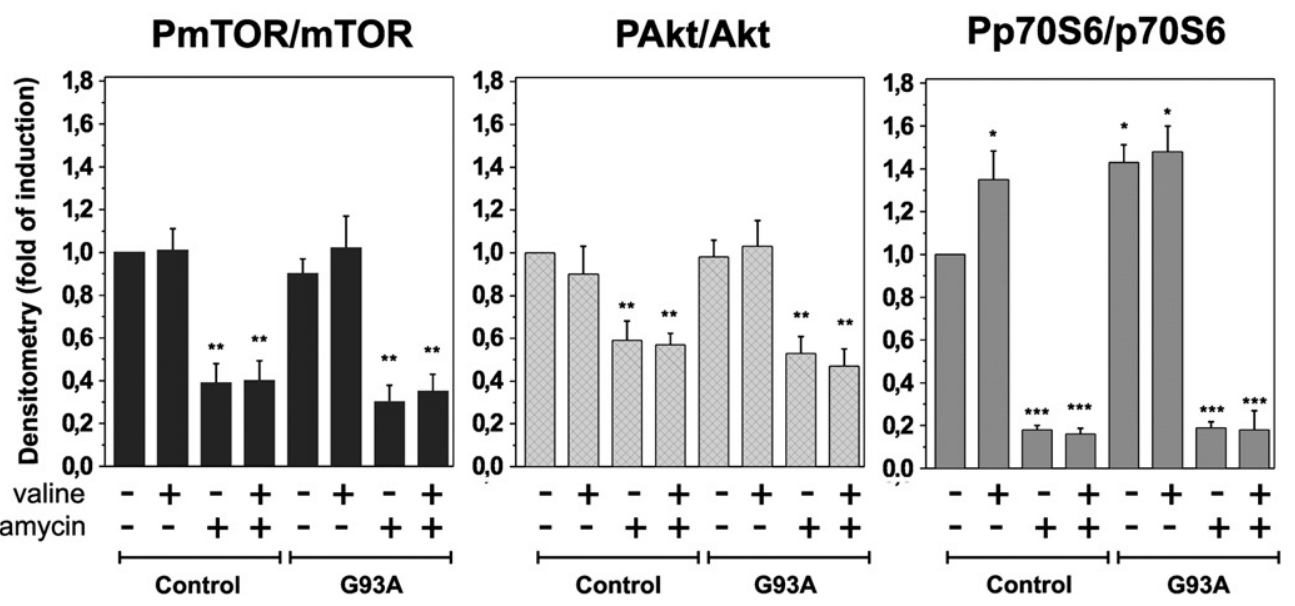

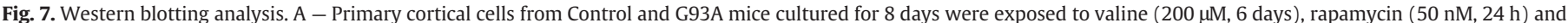

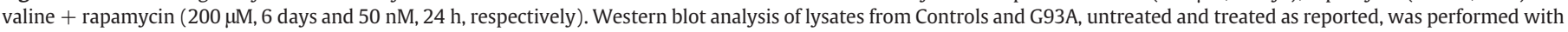

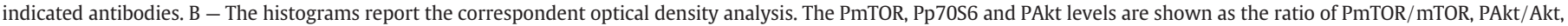

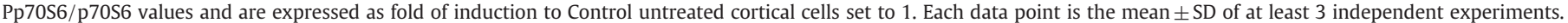
Statistically significant differences were calculated by ANOVA followed by Bonferroni correction $\left({ }^{*} \mathrm{P}<0.05\right.$; ${ }^{* *} \mathrm{P}<0.01,{ }^{* * *} \mathrm{P}<0.001$ versus Control neurons).

In addition, to verify whether a diet enriched with BCAAs induces any alterations in the electrical cortical properties, we fed the pregnant mouse with this diet from the plug day to birth and the offspring until the experimental days (P29-31). The mean weight for Control $(20.4 \pm 1.7 \mathrm{~g}, \mathrm{n}=5)$, G93A $(20.3 \pm 0.8 \mathrm{~g}, \mathrm{n}=5)$ and BCAAtreated $(19 \pm 2.5 \mathrm{~g}, \mathrm{n}=6)$ mice when utilized for the electrophysiological recordings was not significantly different among the three groups ( $P>0.05$, ANOVA followed by Bonferroni correction).

Nissl staining demonstrated that all the recorded filled neurons were observed in Layer V of area M1 of cerebral cortex (Figs. 9A, B). Further, biocytin labeling confirmed that all the recorded filled cells were indeed classical spiny pyramidal neurons with a triangularshaped soma, a large apical dendrite and multiple basal dendrites (Figs. 9 C, $\mathrm{C}^{\prime}$ ).
In all tested Control, G93A and BCAA-treated neurons, the resting membrane potential, the capacitance and the membrane resistance were not significantly different. This indicates that the passive membrane properties were unaffected by mutated human transgene over-expression and by BCAA treatment (Table 2). Further, we analyzed whether cortical slices from G93A and BCAA-treated male mice displayed increased intrinsic excitability compared to Control mice. We recorded action potential firing in response to depolarizing current steps (Fig. 10A). For all injected currents equal to or above $+100 \mathrm{pA}$, the firing frequency in G93A cortical neurons $(\mathrm{n}=9)$, and in BCAA-treated neurons $(n=6)$ was significantly higher than in Control mice $(n=7 ; \mathrm{P}<0.05$, one-way ANOVA, Fig. 10B). Over the range of injected currents in which the frequency was significantly different $(+100 /+200 \mathrm{pA})$, it varied from $7.38 \pm 7.67 \mathrm{~Hz}$ to $23.98 \pm$ 
A

\section{Control}
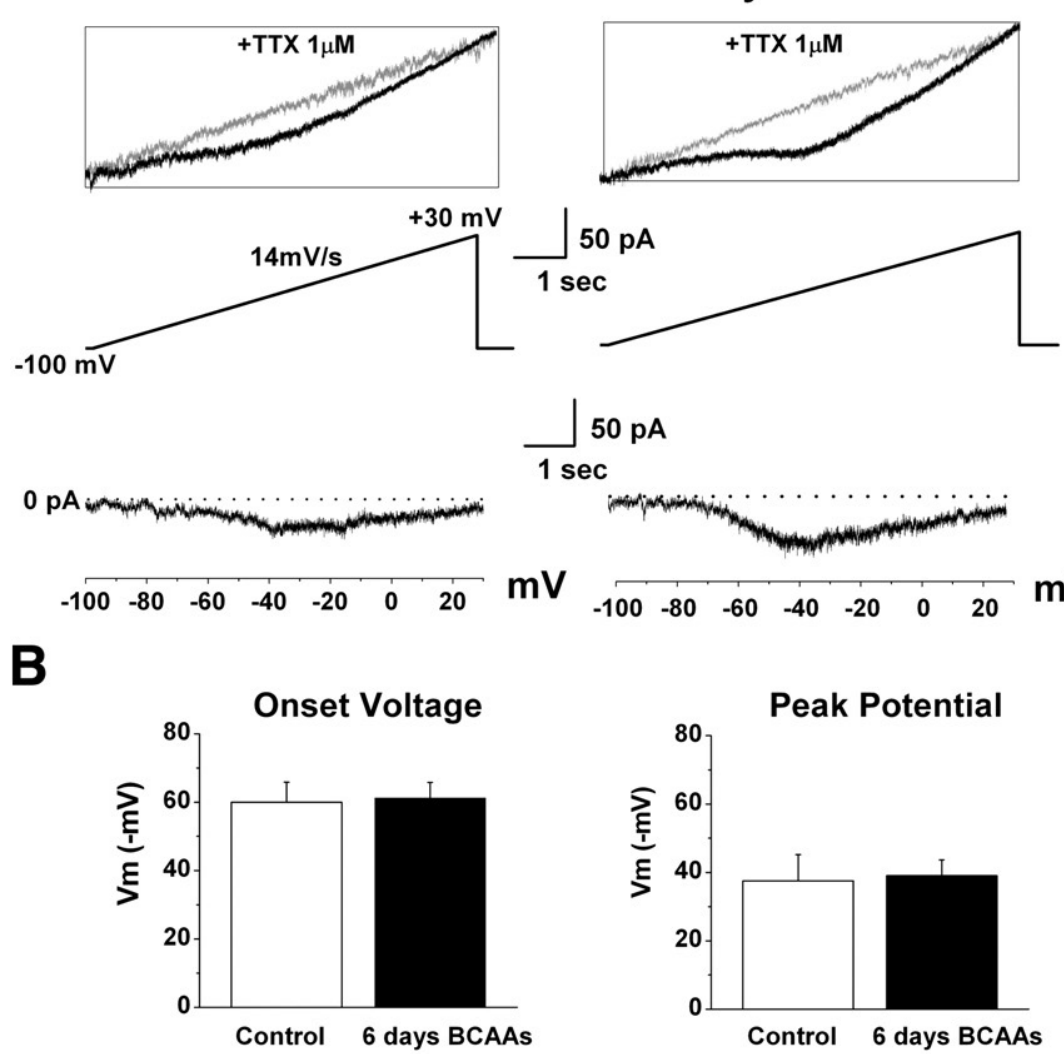

Current

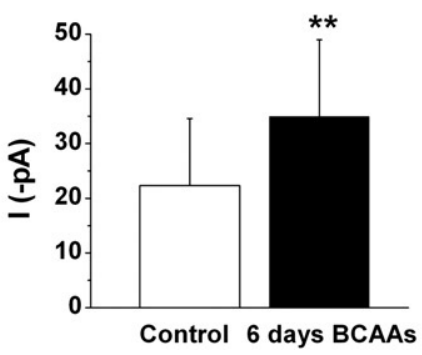

6 days BCAAs

$50 \mathrm{pA}$

1 sec

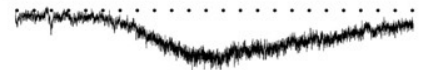

$\mathrm{mV}$
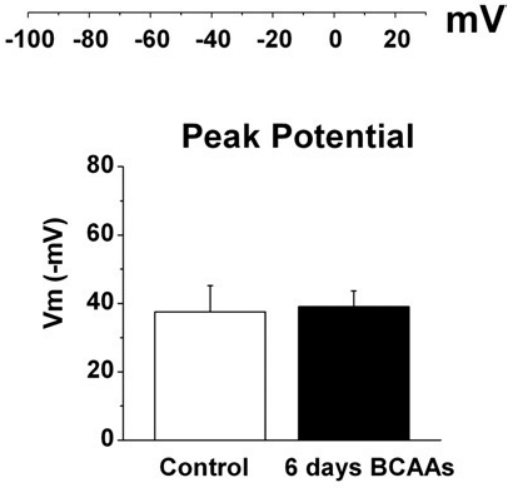

Current Density

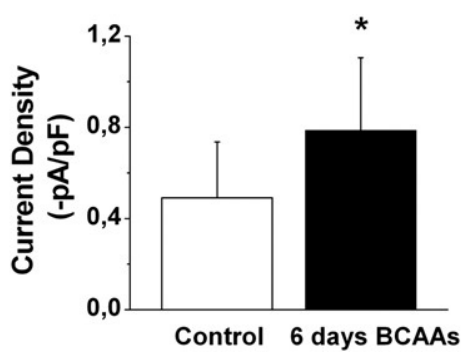

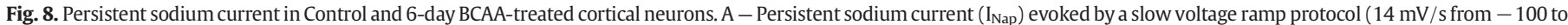

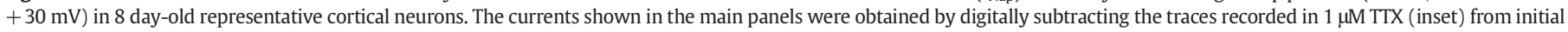

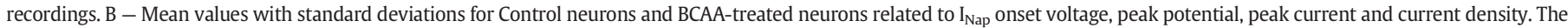
values related to peak current and current density are statistically different in Control and 6-day BCAA-treated cortical neurons (unpaired $t$-Student test, ${ }^{*} \mathrm{P}<0.05$, ${ }^{* *} \mathrm{P}<0.02$ ).
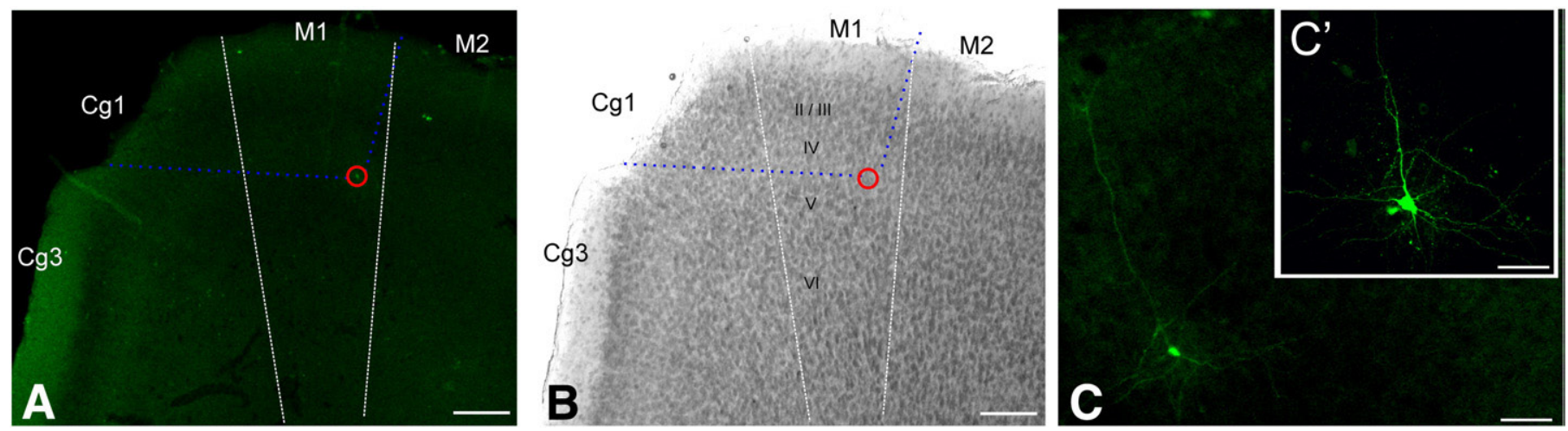

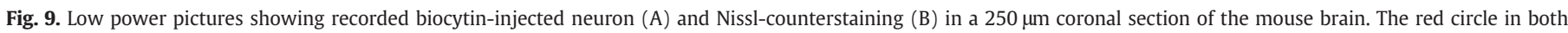

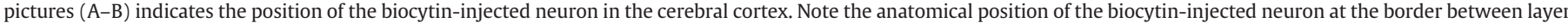

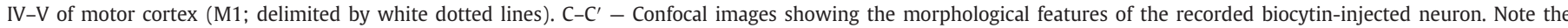

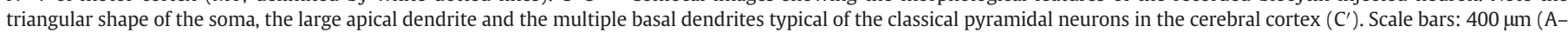
B); $200 \mu \mathrm{m}(\mathrm{C})$ and $50 \mu \mathrm{m}\left(\mathrm{C}^{\prime}\right)$. 
Table 2

Motor cortex neuron properties. Averaged cell properties are calculated for Control, G93A and BCAA motor cortex neurons from P29-P31 mice. The values are not statistically different (ANOVA test, $\mathrm{P}>0.05$ ).

\begin{tabular}{lllc}
\hline & $\begin{array}{l}\text { Resting membrane } \\
\text { potential }(\mathrm{mV})\end{array}$ & $\begin{array}{l}\text { Resistance } \\
(\mathrm{M} \Omega)\end{array}$ & $\begin{array}{l}\text { Capacitance } \\
(\mathrm{pF})\end{array}$ \\
\hline Control $(\mathrm{n}=7)$ & $-63.2 \pm 4.4$ & $54.5 \pm 30.4$ & $79.7 \pm 5.2$ \\
G93A $(\mathrm{n}=9)$ & $-66.5 \pm 4.3$ & $61.7 \pm 21.5$ & $72 \pm 12.7$ \\
BCAAs $(\mathrm{n}=6)$ & $-66 \pm 4.4$ & $54.7 \pm 14.1$ & $74.7 \pm 13.7$ \\
\hline
\end{tabular}

9.51 Hz for Control neurons, from $19.21 \pm 9.86 \mathrm{~Hz}$ to $47.76 \pm 17.13 \mathrm{~Hz}$ for G93A cortical neurons and from $19.54 \pm 4.27 \mathrm{~Hz}$ to $44.3 \pm 8.25 \mathrm{~Hz}$ for BCAA-treated neurons. Interestingly, G93A neurons showed an excitability curve (Fig. 10B) which almost completely overlapped that of BCAA-treated neurons.

The persistent sodium current is known to be involved in repetitive firing by promoting rapid depolarization to the threshold during interspike intervals (Levin et al., 2006; Llinas and Sugimori, 1980; Raman and Bean, 1997). In addition, it has been shown that this current increases in G93A neurons showing hyperexcitability (Kuo et al., 2005; Pieri et al., 2009; van Zundert et al., 2008). Since in the present paper a significant increase in this current has been found in cultured BCAA-treated cortical neurons, we tested Riluzole $(10 \mu \mathrm{M})$ to determine whether the hyperexcitability in G93A and BCAA-treated neurons was reduced by decreasing the amplitude of the persistent sodium current (Fig. 11A). In our experimental conditions, a low dose

A

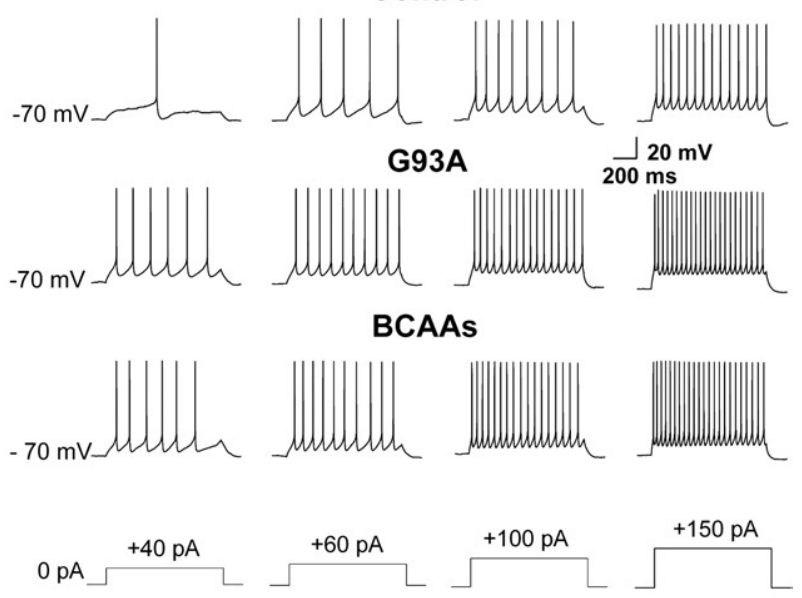

B

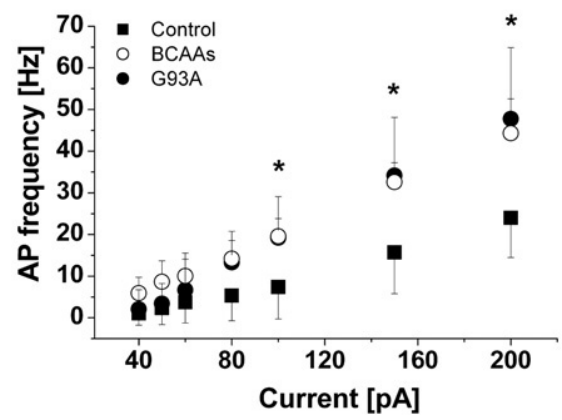

Fig. 10. Repetitive firing properties for Control, G93A and BCAA-treated mice. A Sample traces of Control, G93A and BCAA-treated mice showing action potentials (AP) evoked by rectangular depolarizing current pulses $(+40,+60,+100$ and $+150 \mathrm{pA}$, $1 \mathrm{~s}$ ) from a holding potential of $-70 \mathrm{mV}$. B - Means and standard deviations of AP frequencies plotted against injected currents $(+40 /+200 \mathrm{pA})$, showing that the intrinsic excitability in G93A ( $n=9)$ and in BCAAs $(n=6)$ is significantly higher than in Control mice ( $\mathrm{n}=7$; ANOVA test, $\left.{ }^{*} \mathrm{P}<0.05\right)$.
A
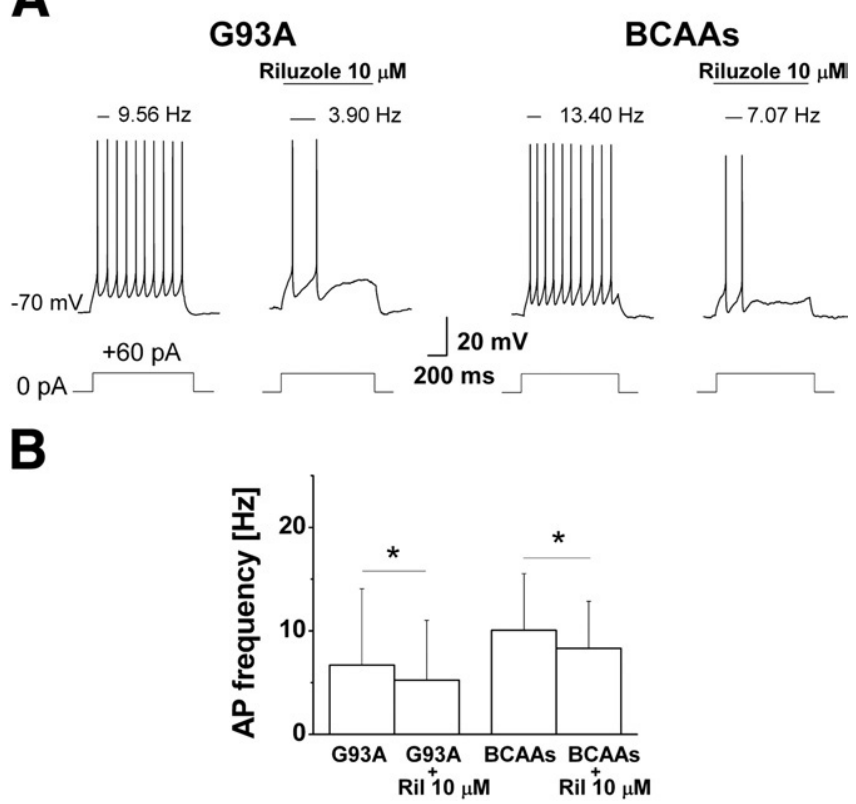

Fig. 11. Effect of riluzole on single neuronal excitability. A - Representative current evoked firing discharge ( $+60 \mathrm{pA}, 1 \mathrm{~s})$ in G93A and BCAA neurons in control conditions and during the application of $10 \mu \mathrm{M}$ Riluzole. The drug is able to reduce the action potential frequencies which are shown above each trace $B-$ Bar histogram showing the reduction of action potential frequency in G93A $(5.23 \pm 5.77 \mathrm{~Hz})$ and BCAAs $(8.31 \pm$ $4.54 \mathrm{~Hz}$ ) neurons in presence of $10 \mu \mathrm{M}$ Riluzole. The difference is statistically significant (paired $t$-Student test, ${ }^{*} \mathrm{P}<0.05$ )

of Riluzole proved capable of reducing cortical frequency (Fig. 11B) both in G93A and in BCAA-treated mice, thus indicating that this current was involved in the observed hyperexcitability.

\section{Discussion}

The higher risk factor of ALS among Italian soccer players that previous epidemiological paper have reported, is still debated (AlChalabi and Leigh, 2005; Armon, 2007; Belli and Vanacore, 2005, 2008; Beretta et al., 2003; Chio et al., 2005, 1999; Vanacore et al., 2006), although different hypotheses have been proposed to explain this possible higher mortality rate. Among these hypothesis, heavy physical exercise, football-specific trauma and microtrauma, exposure to pesticides used on playing fields, use of illegal toxic substances or chronic misuse of drugs, prevalently anti-inflammatory and dietary supplements (Belli and Vanacore, 2005; Chio et al., 2005) have been proposed. Among the dietary supplements, one of the hypotheses involves the abuse of BCAAs in intense sport activities, as was previously speculatively reported (Belli and Vanacore, 2005; Vanacore et al., 2006).

In the present study, we show that BCAAs induce hyperexcitability both in cultured cortical neurons and in motor cortex neurons recorded from cortical slices of mice fed with a BCAA-enriched diet. This hyperexcitability is due specifically to the branched-chain amino acids since phenylalanine and alanine, amino acids with an aromatic chain and without any lateral chain respectively, are unable in cultured cortical neurons to induce any significant alteration in the cellular bursting properties. Interestingly, the hyperexcitability in BCAA-treated neurons in culture is reversed in a dose- and concentration dependent-manner by rapamycin which is also able to reverse that previously reported in G93A cultured cortical neurons (Pieri et al., 2009).

Hyperexcitability is a neuronal feature in ALS. Indeed, a large body of evidence, from previous neurophysiological studies in ALS patients, indicated an abnormal excitability of cortical and spinal motor 
neurons. These studies used transcranial magnetic stimulation (Eisen, 1992; Eisen et al., 1993, 1996; Mills and Nithi, 1997; Triggs et al., 1992; Vucic and Kiernan, 2008; Yokota et al., 1996; Zanette et al., 2002) and different functional neuroimaging and neurophysiological techniques (Brooks et al., 2000; Kew et al., 1993; Zanette et al., 2002). In addition, in the G93A mouse model of ALS, hyperexcitability was recently reported in cultured cortical neurons (Pieri et al., 2009; Stys, 2005), in spinal motor neurons (Kuo et al., 2004, 2005; Tamura et al., 2006) and in brainstem motor neurons (van Zundert et al., 2008).

Neuronal hyperexcitability may contribute to excitotoxic vulnerability. Calcium enters the neurons during each action potential through voltage-dependent $\mathrm{Ca}^{2+}$ channels. Thus, neurons with an increased number of action potentials reach a higher calcium concentration per unit of input which activates toxic pathways (Powers and Binder, 2001). Previous papers reported that cortical abnormalities may be observed in presymptomatic ALS patients (Turner et al., 2005; Vucic and Kiernan, 2007) and that in the G93A mouse model the degeneration of spinal cord motor neurons is secondary to dysfunction within CNS motor pathways, i.e. within the primary motor cortex, corticospinal tract and bulbospinal pathways (Browne et al., 2006). Since cortical hyperexcitability is a feature of presymptomatic ALS (Turner et al., 2005; Vucic and Kiernan, 2007), it has been proposed that the initial abnormality occurs within the motor cortex, with anterograde excitotoxicity underlying subsequent anterior horn cell degeneration (Eisen and Weber, 2001), Consequently, if cortical abnormalities are identified in the early stage of the disease, agents able to reduce cortical hyperexcitability may be administered, thus slowing down the progress of the disease and prolonging survival.

In the first instance we report herein that pyramidal neurons from G93A motor cortex slices present hyperexcitability and that, interestingly, their excitability is comparable to that observed in BCAAtreated neurons. In fact, our data indicate that high doses of BCAAs, if administered over a long period, induce hyperexcitability both in cultured cortical neurons and in pyramidal neurons from motor cortex slices of mice fed with a BCAA-enriched diet. We show that the cause of this hyperexcitability seems to be due to an increased density of the persistent sodium current in valine-treated neurons, as previously observed in G93A cortical neurons (Pieri et al., 2009). In pyramidal neurons from mice fed with BCAAs, the hyperexcitability, detected through increased frequencies of action potentials, is probably also due to a similar mechanism because it was reduced by low concentrations of riluzole (Kuo et al., 2005; Pieri et al., 2009; Tamura et al., 2006; van Zundert et al., 2008). In fact riluzole, a drug currently utilized in clinical treatment (Bensimon et al., 1994), significantly decreases the firing frequency in these neurons being able to suppress the persistent sodium current to a greater extent than the fast transient sodium current (Urbani and Belluzzi, 2000; Zona et al., 1998). The valine effect seems to be limited to inducing neuronal hyperexcitability because the viability of both Control and G93A cells treated with valine was not significantly different in our experimental conditions compared to untreated neurons. Moreover, the viable cells in G93A cultures seem not to be significantly different compared to Control cells. Interestingly the increased level of p70S6 phosphorylation in G93A cultures treated with valine was comparable to that of G93A untreated neurons, indicating the lack of synergic effect on G93A neuronal excitability. Amino acids not only participate as substrates in metabolic pathways, but can also act as regulators of signal transduction pathways. In the nervous system, glutamate and GABA are major neurotransmitters and aspartate and glycine also play roles in neurotransmission (Ishizuka et al., 2008). However, the potential signaling roles of the other amino acids in the CNS are less characterized because specific receptors have not been identified (Ishizuka et al., 2008). Neurons and glia express several amino acid transporters and these amino acids may trigger signaling cascades after being taken up into the cells (Broer, 2006; Smith, 2000; Takanaga et al., 2005). The BCAAs readily cross the blood-brain barrier in exchange with glutamine, and are the major external source of nitrogen for the formation of glutamate and glutamine in the brain (Block and Harper, 1991; Chuang et al., 1995; Cooper and Plum, 1987; LaNoue et al., 2001; Lieth et al., 2001; Yudkoff, 1997).

Previous papers suggested that the intracellular concentrations of some amino acids, in particular the BCAAs, are important regulators of the mTOR pathway (Beugnet et al., 2003; Christie et al., 2002; Dennis et al., 2001; Gulati and Thomas, 2007; Proud, 2007; Tokunaga et al., 2004), although their mechanism of action remains obscure. The current high level of interest in signaling through mTOR reflects its ability to integrate multiple signals to control several cell functions (Wullschleger et al., 2006; Yang and Guan, 2007). The protein kinase mTOR is involved in controlling cell growth and size, and overactivation of mTOR signaling has been linked to human diseases, including cancer (Easton and Houghton, 2006; Lee et al., 2007), ageing and type 2 diabetes (Dann et al., 2007). Moreover, a large body of evidence points to a relation between mTOR and hamartoma syndromes (Inoki et al., 2005), cardiac hypertrophy (Inoki et al., 2005; Proud, 2004) and interestingly, it has been shown that inhibition of mTOR by rapamycin (Foster and Toschi, 2009; Thoreen and Sabatini, 2009) ameliorates some of the symptoms observed in animal models of Huntington disease (Ravikumar et al., 2004). Recently, it has also been reported that mTOR signaling is involved in epileptogenesis and it has been hypothesized that mTOR inhibitor could be useful as antiepileptogenic therapy (Zeng et al., 2009). Interestingly, our data indicate that rapamycin is able to reduce the hyperexcitability in cultured cortical neurons treated with BCAAs and in G93A cultured cortical neurons (Pieri et al., 2009), whereas it is ineffective on the Control neuron excitability. These findings seem to indicate the involvement of mTOR pathway in the neuronal excitability of G93A and valine-treated neurons, probably through an indirect mechanism of action that could be mediated by the glial cells, involved in the ALS pathology, as previously reported (Bogaert et al., 2010; Di Giorgio et al., 2007). Moreover, our data have shown, through western blotting analysis, altered levels of p70S6 phosphorylation, a substrate of mTOR pathway, in BCAA-treated neurons and in G93A neurons. mTOR protein kinase exists in two distinct complexes, mTOR Complex 1 (TORC1) and mTOR Complex 2 (Wullschleger et al., 2006), with a different sensitivity to rapamycin (Foster and Toschi, 2009). Both complexes are regulated by hormones and growth factors, but only mTOR Complex 1 is acutely regulated by nutrients, such as amino acids and glucose (Dann et al., 2007; Krebs et al., 2007). The mechanism by which they activate TORC1 is largely unknown. Previous studies have reported that BCAAs modulate the mTOR pathway in different non neuronal cells (Kakazu et al., 2007; Perez de Obanos et al., 2006) and in muscle cell line (Herningtyas et al., 2008). It has also been reported that in cortical neurons the branched-chain amino acid leucine activates and phosphorylates p70 ribosomal protein S6 kinase (p70S6K), a substrate of mTOR, in a rapamycin-sensitive manner (Hara et al., 1998; Kimball et al., 1999; Xu et al., 1998). This activation is mediated by system L-amino acid transporter(s) (Ishizuka et al., 2008). Interestingly, p70S6K is a multipotent kinase that regulates translation, cell size, cell growth, and cell survival (Ishizuka et al., 2008).

Our findings clearly show that, similarly to the leucine effects (Ishizuka et al., 2008), p70S6 phosphorylation is increased both in valine-treated neurons and also in G93A neurons, in a rapamycinsensitive manner. Moreover, our results indicate that rapamycin may reduce the hyperexcitability of G93A and valine-exposed neurons through an indirect mechanism of action that could be mediated by the glial cells. Interestingly, previous papers have supposed that the mTOR pathway may regulate the electrical activity of the single neuron and mediate mechanisms of neuronal excitability (RaabGraham et al., 2006; Yue et al., 2000; Zeng et al., 2009), although the mechanism of action is still unknown. In fact, the relationship between the mTOR pathway and the ionic channel functionality is 
far from being known, in particular regarding the persistent sodium current on account of the nature of this current. In fact, an important yet unanswered question is whether persistent and fast inactivating sodium currents arise from different sets of sodium channels or whether the persistent sodium current results from different gating of the same channel type (Crill, 1996; Kiss, 2008).

In conclusion, together all these data seem to indicate a similar phenotype of neurons treated with BCAAs and neurons from the G93A mouse model of ALS. Moreover, although our findings do not directly support a pathogenic mechanism in ALS, they point to the importance of mTOR substrates in ALS pathology, potentially offering novel avenues for developing therapeutic strategies.

\section{Acknowledgments}

We thank Prof. Nicola Mercuri and Dr. Nicola Vanacore for their helpful comments.

This work was supported by Istituto Superiore di Sanità, Italy [grant no. CVDV/1-2, to C.Z.]; and by Wyeth Lederle S.p.A., to C.Z.

\section{References}

Al-Chalabi, A., Leigh, P.N., 2005. Trouble on the pitch: are professional football players at increased risk of developing amyotrophic lateral sclerosis? Brain 128, 451-453.

Armon, C., 2007. Sports and trauma in amyotrophic lateral sclerosis revisited. J. Neurol. Sci. 262, 45-53.

Avruch, J., Belham, C., Weng, Q., Hara, K., Yonezawa, K., 2001. The p70 S6 kinase integrates nutrient and growth signals to control translational capacity. Prog. Mol. Subcell. Biol. 26, 115-154.

Belli, S., Vanacore, N., 2005. Proportionate mortality of Italian soccer players: is amyotrophic lateral sclerosis an occupational disease? Eur. J. Epidemiol. 20, 237-242.

Belli, S., Vanacore, N., 2008. Sports and amyotrophic lateral sclerosis. J. Neurol. Sci. 269, 191 author reply 191-192.

Bensimon, G., Lacomblez, L., Meininger, V., 1994. A controlled trial of riluzole in amyotrophic lateral sclerosis. ALS/Riluzole Study Group. N. Engl. J. Med. 330, 585-591.

Beretta, S., Carri, M.T., Beghi, E., Chio, A., Ferrarese, C., 2003. The sinister side of Italian soccer. Lancet Neurol. 2, 656-657.

Beugnet, A., Tee, A.R., Taylor, P.M., Proud, C.G., 2003. Regulation of targets of mTOR (mammalian target of rapamycin) signalling by intracellular amino acid availability. Biochem. J. 372, 555-566.

Block, K.P., Harper, A.E., 1991. High levels of dietary amino and branched-chain alphaketo acids alter plasma and brain amino acid concentrations in rats. J. Nutr. 121, 663-671.

Bogaert, E., d'Ydewalle, C., Van Den Bosch, L., 2010. Amyotrophic lateral sclerosis and excitotoxicity: from pathological mechanism to therapeutic target. CNS Neurol. Disord. Drug Targets 9, 297-304.

Broer, S., 2006. The SLC6 orphans are forming a family of amino acid transporters. Neurochem. Int. 48, 559-567.

Brooks, B.R., Bushara, K., Khan, A., Hershberger, J., Wheat, J.O., Belden, D., Henningsen, $H$, 2000. Functional magnetic resonance imaging (fMRI) clinical studies in ALSparadigms, problems and promises. Amyotroph. Lateral Scler. Other Motor Neuron Disord 1 (Suppl 2), S23-S32.

Browne, S.E, Yang, L, DiMauro, J.P., Fuller, S.W., Licata, S.C. Beal, M.F., 2006. Bioenergetic abnormalities in discrete cerebral motor pathways presage spinal cord pathology in the G93A SOD1 mouse model of ALS. Neurobiol. Dis. 22, 599-610.

Chio, A., Cucatto, A., Calvo, A., Terreni, A.A., Magnani, C., Schiffer, D., 1999. Amyotrophic lateral sclerosis among the migrant population to Piemonte, northwestern Italy. J. Neurol. 246, 175-180.

Chio, A., Benzi, G., Dossena, M., Mutani, R., Mora, G., 2005. Severely increased risk of amyotrophic lateral sclerosis among Italian professional football players. Brain 128 , 472-476.

Christie, G.R., Hajduch, E., Hundal, H.S., Proud, C.G., Taylor, P.M., 2002. Intracellular sensing of amino acids in Xenopus laevis oocytes stimulates p70 S6 kinase in a target of rapamycin-dependent manner. J. Biol. Chem. 277, 9952-9957.

Chuang, D.T., Davie, J.R., Wynn, R.M., Chuang, J.L., Koyata, H., Cox, R.P., 1995. Molecular basis of maple syrup urine disease and stable correction by retroviral gene transfer J. Nutr. 125, 1766S-1772S.

Contreras, D., 2004. Electrophysiological classes of neocortical neurons. Neural Netw. $17,633-646$

Cooper, A.J., Plum, F., 1987. Biochemistry and physiology of brain ammonia. Physiol Rev. 67, 440-519.

Cota, D., Proulx, K., Smith, K.A., Kozma, S.C., Thomas, G., Woods, S.C., Seeley, R.J., 2006. Hypothalamic mTOR signaling regulates food intake. Science 312, 927-930.

Crill, W.E., 1996. Persistent sodium current in mammalian central neurons. Annu. Rev. Physiol. 58, 349-362.

Dann, S.G., Selvaraj, A., Thomas, G., 2007. mTOR Complex1-S6K1 signaling: at the crossroads of obesity, diabetes and cancer. Trends Mol. Med. 13, 252-259.

Dennis, P.B., Jaeschke, A., Saitoh, M., Fowler, B., Kozma, S.C., Thomas, G., 2001 Mammalian TOR: a homeostatic ATP sensor. Science 294, 1102-1105.
Di Giorgio, F.P., Carrasco, M.A., Siao, M.C., Maniatis, T., Eggan, K., 2007. Non-cell autonomous effect of glia on motor neurons in an embryonic stem cell-based ALS model. Nat. Neurosci. 10, 608-614.

Easton, J.B., Houghton, P.J., 2006. mTOR and cancer therapy. Oncogene 25, 6436-6446.

Eisen, A , 1992. Corticomotoneurons are hyperexcitabile early in amyotrophic lateral sclerosis: a magnetic stimulation study. Ann. Neurol. 32, 272.

Eisen, A., Weber, M., 2001. The motor cortex and amyotrophic lateral sclerosis. Muscle Nerve 24, 564-573.

Eisen, A., Pant, B., Stewart, H., 1993. Cortical excitability in amyotrophic lateral sclerosis: a clue to pathogenesis. Can. J. Neurol. Sci. 20, 11-16.

Eisen, A., Entezari-Taher, M., Stewart, H., 1996. Cortical projections to spinal motoneurons: changes with aging and amyotrophic lateral sclerosis. Neurology 46, 1396-1404

Foster, D.A., Toschi, A., 2009. Targeting mTOR with rapamycin: one dose does not fit all. Cell Cycle 8, 1026-1029.

Franklin, K., Paxinos, G., 1997. The Mouse Brain. Academic press, San Diego.

Guatteo, E., Carunchio, I., Pieri, M., Albo, F., Canu, N., Mercuri, N.B., Zona, C., 2007. Altered calcium homeostasis in motor neurons following AMPA receptor but not voltage-dependent calcium channels' activation in a genetic model of amyotrophic lateral sclerosis. Neurobiol. Dis. 28, 90-100.

Gulati, P., Thomas, G., 2007. Nutrient sensing in the mTOR/S6K1 signalling pathway. Biochem. Soc. Trans. 35, 236-238.

Gurney, M.E., Pu, H., Chiu, A.Y., Dal Canto, M.C., Polchow, C.Y., Alexander, D.D., Caliendo, J., Hentati, A., Kwon, Y.W., Deng, H.X., et al., 1994. Motor neuron degeneration in mice that express a human $\mathrm{Cu}, \mathrm{Zn}$ superoxide dismutase mutation. Science 264, 1772-1775.

Hara, K., Yonezawa, K., Weng, Q.P., Kozlowski, M.T., Belham, C., Avruch, J., 1998. Amino acid sufficiency and mTOR regulate p70 S6 kinase and eIF-4E BP1 through a common effector mechanism. J. Biol. Chem. 273, 14484-14494.

Herningtyas, E.H., Okimura, Y., Handayaningsih, A.E., Yamamoto, D., Maki, T., Iida, K., Takahashi, Y., Kaji, H., Chihara, K., 2008. Branched-chain amino acids and arginine suppress MaFbx/atrogin-1 mRNA expression via mTOR pathway in C2C12 cell line. Biochim. Biophys. Acta 1780, 1115-1120.

Inoki, K., Corradetti, M.N., Guan, K.L., 2005. Dysregulation of the TSC-mTOR pathway in human disease. Nat. Genet. 37, 19-24.

Ishizuka, Y., Kakiya, N., Nawa, H., Takei, N., 2008. Leucine induces phosphorylation and activation of p70S6K in cortical neurons via the system $\mathrm{L}$ amino acid transporter. J. Neurochem. 106, 934-942.

Italian ALS study group, 1993. Branched-chain amino acids and amyotrophic lateral sclerosis: a treatment failure? The Italian ALS Study Group. Neurology, pp. 2466-2470.

Kakazu, E., Kanno, N., Ueno, Y., Shimosegawa, T., 2007. Extracellular branched-chain amino acids, especially valine, regulate maturation and function of monocytederived dendritic cells. J. Immunol. 179, 7137-7146.

Kew, J.J., Leigh, P.N., Playford, E.D., Passingham, R.E., Goldstein, L.H., Frackowiak, R.S., Brooks, D.J., 1993. Cortical function in amyotrophic lateral sclerosis. A positron emission tomography study. Brain 116 (Pt 3), 655-680.

Kimball, S.R., Shantz, L.M., Horetsky, R.L., Jefferson, L.S., 1999. Leucine regulates translation of specific mRNAs in L6 myoblasts through mTOR-mediated changes in availability of eIF4E and phosphorylation of ribosomal protein S6. J. Biol. Chem. 274, 11647-11652.

Kiss, T., 2008. Persistent Na-channels: origin and function. A review. Acta Biol. Hung. 59 (Suppl), 1-12.

Krebs, M., Brunmair, B., Brehm, A., Artwohl, M., Szendroedi, J., Nowotny, P., Roth, E., Furnsinn, C., Promintzer, M., Anderwald, C. Bischof, M. Roden, M. 2007. The mammalian target of rapamycin pathway regulates nutrient-sensitive glucose uptake in man. Diabetes 56, 1600-1607.

Kuo, J.J., Schonewille, M., Siddique, T., Schults, A.N., Fu, R., Bar, P.R., Anelli, R., Heckman, C.J., Kroese, A.B., 2004. Hyperexcitability of cultured spinal motoneurons from presymptomatic ALS mice. J. Neurophysiol. 91, 571-575.

Kuo, J.J., Siddique, T., Fu, R., Heckman, C.J., 2005. Increased persistent $\mathrm{Na}(+)$ current and its effect on excitability in motoneurones cultured from mutant SOD1 mice. J. Physiol. 563, 843-854.

Kurtzke, J.F., Beebe, G.W., 1980. Epidemiology of amyotrophic lateral sclerosis: 1. A case-control comparison based on ALS deaths. Neurology 30, 453-462.

LaNoue, K.F. Berkich, D.A. Conway, M. Barber, A.J. Hu, LY, Taylor, C, Hutson, S, 2001. Role of specific aminotransferases in de novo glutamate synthesis and redox shuttling in the retina. J. Neurosci. Res. 66, 914-922.

Lee, C.H., Inoki, K., Guan, K.L., 2007. mTOR pathway as a target in tissue hypertrophy. Annu. Rev. Pharmacol. Toxicol. 47, 443-467.

Levin, S.I., Khaliq, Z.M., Aman, T.K., Grieco, T.M., Kearney, J.A., Raman, I.M., Meisler, M.H., 2006. Impaired motor function in mice with cell-specific knockout of sodium channel Scn8a (NaV1.6) in cerebellar purkinje neurons and granule cells. J. Neurophysiol. 96, 785-793.

Li, H., Prince, D.A., 2002. Synaptic activity in chronically injured, epileptogenic sensorymotor neocortex. J. Neurophysiol. 88, 2-12.

Lieth, E., LaNoue, K.F., Berkich, D.A., Xu, B., Ratz, M., Taylor, C., Hutson, S.M., 2001 Nitrogen shuttling between neurons and glial cells during glutamate synthesis. J. Neurochem. 76, 1712-1723.

Llinas, R., Sugimori, M., 1980. Electrophysiological properties of in vitro Purkinje cell somata in mammalian cerebellar slices. J. Physiol. 305, 171-195.

Lu, J.T., Li, C.Y., Zhao, J.P., Poo, M.M., Zhang, X.H., 2007. Spike-timing-dependent plasticity of neocortical excitatory synapses on inhibitory interneurons depends on target cell type. J. Neurosci. 27, 9711-9720.

Mills, K.R., Nithi, K.A., 1997. Corticomotor threshold is reduced in early sporadic amyotrophic lateral sclerosis. Muscle Nerve 20,1137-1141.

Ohtani, M., Sugita, M., Maruyama, K., 2006. Amino acid mixture improves training efficiency in athletes. J. Nutr. 136, 538S-543S. 
Oldendorf, W.H., 1971. Brain uptake of radiolabeled amino acids, amines, and hexoses after arterial injection. Am. J. Physiol. 221, 1629-1639.

Perez de Obanos, M.P., Lopez Zabalza, M.J., Prieto, J., Herraiz, M.T., Iraburu, M.J., 2006. Leucine stimulates procollagen alpha1(I) translation on hepatic stellate cells through ERK and PI3K/Akt/mTOR activation. J. Cell. Physiol. 209, 580-586.

Pieri, M., Carunchio, I., Curcio, L., Mercuri, N.B., Zona, C., 2009. Increased persistent sodium current determines cortical hyperexcitability in a genetic model of amyotrophic lateral sclerosis. Exp. Neurol. 215, 368-379.

Plaitakis, A., 1990. Glutamate dysfunction and selective motor neuron degeneration in amyotrophic lateral sclerosis: a hypothesis. Ann. Neurol. 28, 3-8.

Platell, C., Kong, S.E., McCauley, R., Hall, J.C., 2000. Branched-chain amino acids. J. Gastroenterol. Hepatol. 15, 706-717.

Powers, R.K., Binder, M.D., 2001. Input-output functions of mammalian motoneurons. Rev. Physiol. Biochem. Pharmacol. 143, 137-263.

Proud, C.G., 2002. Regulation of mammalian translation factors by nutrients. Eur. J. Biochem. 269, 5338-5349.

Proud, C.G., 2004. Ras, PI3-kinase and mTOR signaling in cardiac hypertrophy. Cardiovasc. Res. 63, 403-413.

Proud, C.G., 2007. Amino acids and mTOR signalling in anabolic function. Biochem. Soc. Trans. 35, 1187-1190.

Raab-Graham, K.F., Haddick, P.C., Jan, Y.N., Jan, L.Y., 2006. Activity- and mTOR-dependent suppression of Kv1.1 channel mRNA translation in dendrites. Science 314, 144-148.

Raman, I.M., Bean, B.P., 1997. Resurgent sodium current and action potential formation in dissociated cerebellar Purkinje neurons. J. Neurosci. 17, 4517-4526.

Ravikumar, B., Vacher, C., Berger, Z., Davies, J.E., Luo, S., Oroz, L.G., Scaravilli, F., Easton, D.F., Duden, R., O'Kane, C.J., Rubinsztein, D.C., 2004. Inhibition of mTOR induces autophagy and reduces toxicity of polyglutamine expansions in fly and mouse models of Huntington disease. Nat. Genet. 36, 585-595.

Sandsmark, D.K., Pelletier, C., Weber, J.D., Gutmann, D.H., 2007. Mammalian target of rapamycin: master regulator of cell growth in the nervous system. Histol. Histopathol. 22, 895-903.

Sarbassov, D.D., Ali, S.M., Sabatini, D.M., 2005. Growing roles for the mTOR pathway. Curr. Opin. Cell Biol. 17, 596-603.

Sarbassov, D.D., Ali, S.M., Sengupta, S., Sheen, J.H., Hsu, P.P., Bagley, A.F., Markhard, A.L., Sabatini, D.M., 2006. Prolonged rapamycin treatment inhibits mTORC2 assembly and Akt/PKB. Mol. Cell 22, 159-168.

Smith, Q.R., 2000. Transport of glutamate and other amino acids at the blood-brain barrier. J. Nutr. 130, 1016S-1022S.

Steriade, M., 2004. Neocortical cell classes are flexible entities. Nat. Rev. Neurosci. 5, 121-134.

Stuart, G.J., Dodt, H.U., Sakmann, B., 1993. Patch-clamp recordings from the soma and dendrites of neurons in brain slices using infrared video microscopy. Pflugers Arch. 423, 511-518.

Stys, P.K., 2005. General mechanisms of axonal damage and its prevention. J. Neurol. Sci. 233, 3-13.

Takanaga, H., Mackenzie, B., Peng, J.B., Hediger, M.A., 2005. Characterization of a branched-chain amino-acid transporter SBAT1 (SLC6A15) that is expressed in human brain. Biochem. Biophys. Res. Commun. 337, 892-900.

Tamura, N., Kuwabara, S., Misawa, S., Kanai, K., Nakata, M., Sawai, S., Hattori, T., 2006. Increased nodal persistent $\mathrm{Na}+$ currents in human neuropathy and motor neuron disease estimated by latent addition. Clin. Neurophysiol. 117, 2451-2458.

Tandan, R., Bromberg, M.B., Forshew, D., Fries, T.J., Badger, G.J., Carpenter, J., Krusinski, P. B., Betts, E.F., Arciero, K., Nau, K., 1996. A controlled trial of amino acid therapy in amyotrophic lateral sclerosis: I. Clinical, functional, and maximum isometric torque data. Neurology 47, 1220-1226.

Tang, S.J., Reis, G., Kang, H., Gingras, A.C., Sonenberg, N., Schuman, E.M., 2002. A rapamycin-sensitive signaling pathway contributes to long-term synaptic plasticity in the hippocampus. Proc. Natl. Acad. Sci. U. S. A. 99, 467-472.
Testa, D., Caraceni, T., Fetoni, V., 1989. Branched-chain amino acids in the treatment of amyotrophic lateral sclerosis. J. Neurol. 236, 445-447.

Thoreen, C.C., Sabatini, D.M., 2009. Rapamycin inhibits mTORC1, but not completely. Autophagy 5, 725-726.

Tokunaga, C., Yoshino, K., Yonezawa, K., 2004. mTOR integrates amino acid- and energy-sensing pathways. Biochem. Biophys. Res. Commun. 313, 443-446.

Triggs, W.J., Macdonell, R.A., Cros, D., Chiappa, K.H., Shahani, B.T., Day, B.J., 1992. Motor inhibition and excitation are independent effects of magnetic cortical stimulation. Ann. Neurol. 32, 345-351.

Tsang, C.K., Qi, H., Liu, L.F., Zheng, X.F., 2007. Targeting mammalian target of rapamycin (mTOR) for health and diseases. Drug Discov. Today 12, 112-124.

Tsubuku, S., Hatayama, K., Katsumata, T., Nishimura, N., Mawatari, K., Smriga, M. Kimura, T., 2004. Thirteen-week oral toxicity study of branched-chain amino acids in rats. Int. J. Toxicol. 23, 119-126.

Turner, M.R., Osei-Lah, A.D., Hammers, A, Al-Chalabi, A., Shaw, C.E., Andersen, P.M. Brooks, D.J., Leigh, P.N., Mills, K.R., 2005. Abnormal cortical excitability in sporadic but not homozygous D90A SOD1 ALS. J. Neurol. Neurosurg. Psychiatry 76 1279-1285.

Urbani, A., Belluzzi, O., 2000. Riluzole inhibits the persistent sodium current in mammalian CNS neurons. Eur. J. Neurosci. 12, 3567-3574.

van Zundert, B., Peuscher, M.H., Hynynen, M., Chen, A., Neve, R.L., Brown Jr., R.H. Constantine-Paton, M., Bellingham, M.C., 2008. Neonatal neuronal circuitry shows hyperexcitable disturbance in a mouse model of the adult-onset neurodegenerative disease amyotrophic lateral sclerosis. J. Neurosci. 28, 10864-10874.

Vanacore, N., Binazzi, A., Bottazzi, M., Belli, S., 2006. Amyotrophic lateral sclerosis in an Italian professional soccer player. Parkinsonism Relat. Disord. 12, 327-329.

Volonte, C., Ciotti, M.T., Battistini, L., 1994. Development of a method for measuring cell number: application to CNS primary neuronal cultures. Cytometry 17, 274-276.

Vucic, S., Kiernan, M.C., 2007. Abnormalities in cortical and peripheral excitability in flail arm variant amyotrophic lateral sclerosis. J. Neurol. Neurosurg. Psychiatry 78 849-852.

Vucic, S., Kiernan, M.C., 2008. Cortical excitability testing distinguishes Kennedy's disease from amyotrophic lateral sclerosis. Clin. Neurophysiol. 119, 1088-1096.

Wullschleger, S., Loewith, R., Hall, M.N., 2006. TOR signaling in growth and metabolism. Cell 124, 471-484.

Xu, G., Kwon, G., Marshall, CA, Lin, T.A, Lawrence Jr JC. McDaniel, M.L., 1998 Branched-chain amino acids are essential in the regulation of PHAS-I and p70 S6 kinase by pancreatic beta-cells. A possible role in protein translation and mitogenic signaling. J. Biol. Chem. 273, 28178-28184.

Yang, Q., Guan, K.L., 2007. Expanding mTOR signaling. Cell Res. 17, 666-681.

Yokota, T., Yoshino, A., Inaba, A., Saito, Y., 1996. Double cortical stimulation in amyotrophic lateral sclerosis. J. Neurol. Neurosurg. Psychiatry 61, 596-600.

Yudkoff, M., 1997. Brain metabolism of branched-chain amino acids. Glia 21, 92-98.

Yue, G., Edinger, R.S., Bao, H.F., Johnson, J.P., Eaton, D.C., 2000. The effect of rapamycin on single ENaC channel activity and phosphorylation in A6 cells. Am. J. Physiol. Cell Physiol. 279, C81-C88.

Zanette, G., Tamburin, S., Manganotti, P., Refatti, N., Forgione, A., Rizzuto, N., 2002 Changes in motor cortex inhibition over time in patients with amyotrophic lateral sclerosis. J. Neurol. 249, 1723-1728.

Zeng, L.H., Xu, L., Gutmann, D.H., Wong, M., 2008. Rapamycin prevents epilepsy in a mouse model of tuberous sclerosis complex. Ann. Neurol. 63, 444-453.

Zeng, L.H., Rensing, N.R., Wong, M., 2009. The mammalian target of rapamycin signaling pathway mediates epileptogenesis in a model of temporal lobe epilepsy. J. Neurosci. 29, 6964-6972.

Zilles, K., 1985. The Cortex of the Rat. Springer-Verlag, Berlin.

Zona, C., Siniscalchi, A., Mercuri, N.B., Bernardi, G., 1998. Riluzole interacts with voltageactivated sodium and potassium currents in cultured rat cortical neurons. Neuroscience 85, 931-938. 